\title{
Arabidopsis Response Regulator 6 (ARR6) Modulates Plant Cell-Wall Composition and Disease Resistance
}

\author{
Laura Bacete, ${ }^{1,2}$ Hugo Mélida, ${ }^{1}$ Gemma López, ${ }^{1}$ Patrick Dabos, ${ }^{3}$ Dominique Tremousaygue, ${ }^{3}$ \\ Nicolas Denancé, ${ }^{3,4}$ Eva Miedes, ${ }^{1,2}$ Vincent Bulone, ${ }^{5,6}$ Deborah Goffner, ${ }^{4}$ and Antonio Molina, ${ }^{1,2,+}$ \\ ${ }^{1}$ Centro de Biotecnología y Genómica de Plantas, Universidad Politécnica de Madrid (UPM)-Instituto Nacional de Investigación \\ y Tecnología Agraria y Alimentaria (INIA), Campus Montegancedo-UPM, 28223-Pozuelo de Alarcón (Madrid), Spain \\ ${ }^{2}$ Departamento de Biotecnología-Biología Vegetal, Escuela Técnica Superior de Ingeniería Agronómica, Alimentaria y de \\ Biosistemas, Universidad Politécnica de Madrid, 28040-Madrid, Spain \\ ${ }^{3}$ LIPM, Université de Toulouse, INRA, CNRS, UPS, Castanet-Tolosan Cedex, France \\ ${ }^{4}$ Laboratoire de Recherche en Sciences Végétales, CNRS, Université Paul Sabatier, UMR 5546, Chemin de Borde Rouge, \\ F-31326 Castanet-Tolosan, France \\ ${ }^{5}$ Royal Institute of Technology (KTH), School of Engineering Sciences in Chemistry, Biotechnology and Health, Division of \\ Glycoscience, AlbaNova University Center, SE-106 91 Stockholm, Sweden \\ ${ }^{6}$ ARC Centre of Excellence in Plant Cell Walls and School of Agriculture, Food and Wine, The University of Adelaide, Waite \\ Campus, Urrbrae, SA 5064, Australia
}

Accepted 4 February 2020.

The cytokinin signaling pathway, which is mediated by Arabidopsis response regulator (ARR) proteins, has been involved in the modulation of some disease-resistance responses. Here, we describe novel functions of ARR6 in the control of plant diseaseresistance and cell-wall composition. Plants impaired in ARRG function (arro) were more resistant and susceptible, respectively, to the necrotrophic fungus Plectosphaerella cucumerina and to the vascular bacterium Ralstonia solanacearum, whereas Arabidopsis plants that overexpress ARR6 showed the opposite phenotypes, which further support a role of $A R R 6$ in the modulation of disease-resistance responses against these pathogens. Transcriptomics and metabolomics analyses revealed that, in arr6 plants, canonical disease-resistance pathways, like those activated by defensive phytohormones, were not altered, whereas immune responses triggered by microbe-associated molecular

Microarray expression data from this article can be found in the Gene Expression Omnibus National Center for Biotechnology Information database under accession number GSE120923.

Current address for Laura Bacete: Institute for Biology, Faculty of Natural Sciences, Norwegian University of Science and Technology, 7491 Trondheim, Norway.

Current address for Nicolas Denancé: GEVES, Station Nationale des Essais de Semences, Laboratoire de Pathologie, Beaucouzé, France.

${ }^{\dagger}$ Corresponding author: A. Molina; antonio.molina@upm.es

Funding: European Commission grant SignWALLINg-624721, Ministerio de Economía y Competitividad grants BES-2013-065010, BIO2012-32910, and BIO2015-64077-R, Agencia Estatal de Investigación grant RTI2018096975-B-I00, Agence Nationale de la Recherche grant WALLTALK ANR-07-GPLA-014, and Severo Ochoa Programme for Centres of Excellence in Research\&Development grant SEV-2016-0672 (2017-2021).

*The $\boldsymbol{e}$-Xtra logo stands for "electronic extra" and indicates that supplementary figures and supplementary tables are published online.

The author(s) declare no conflict of interest.

๑) 2020 The American Phytopathological Society patterns were slightly enhanced. Cell-wall composition of arr6 plants was found to be severely altered compared with that of wild-type plants. Remarkably, pectin-enriched cell-wall fractions extracted from arr6 walls triggered more intense immune responses than those activated by similar wall fractions from wild-type plants, suggesting that arr6 pectin fraction is enriched in wall-related damage-associated molecular patterns, which trigger immune responses. This work supports a novel function of $A R R 6$ in the control of cell-wall composition and disease resistance and reinforces the role of the plant cell wall in the modulation of specific immune responses.

Keywords: Arabidopsis response regulators (ARR), cell wall, cytokinin, damage-associated molecular patterns (DAMPs), disease resistance, immunity, Plectosphaerella cucumerina, Ralstonia solanacearum

Plants are sessile organisms that need to develop robust disease-resistance mechanisms to efficiently defend themselves from pathogens and pests. Plant defense is tightly regulated by a complex network of phytohormones that precisely integrates external and internal cues to maintain homeostasis and coordinate the defense responses at the spatial and temporal levels (Couto and Zipfel 2016; Pieterse et al. 2012). In Arabidopsis, salicylic acid (SA), jasmonic acid (JA), and ethylene (ET) are the most important hormones regulating plant disease-resistance responses (Denancé et al. 2013a; Robert-Seilaniantz et al. 2011; Shigenaga et al. 2017). The SA pathway is usually effective in mediating resistance against biotrophic pathogens, whereas JA and ET pathways are commonly required for immune responses against necrotrophic pathogens and insects (Bari and Jones 2009; Denancé et al. 2013a; Glazebrook 2005). In addition to SA, $\mathrm{JA}$, and ET, other phytohormones may also function as plant immunity modulators and play specific roles in resistance to different types of pathogens (Robert-Seilaniantz et al. 2011; Shigenaga et al. 2017).

Cytokinins have emerged as an important hub integrating defense responses mediated by other hormones (Choi et al. 2011) and have been shown to regulate the expression of 
defense genes and the activation of immune responses as determined in plants treated with cytokinins or in cytokinin-overaccumulating lines (Choi et al. 2010). Cytokinins are a family of $\mathrm{N}^{6}$-substituted adenine derivatives and chemically unrelated phenylurea-type hormones primarily involved in cell growth and differentiation. In Arabidopsis, cytokinins are perceived by Arabidopsis histidine kinases 2 to 4 (AHK2 to AHK4) receptors, which are two-component system proteins that initiate a downstream phosphotransfer cascade that leads to the phosphorylation of Arabidopsis response regulator (ARR) proteins through Arabidopsis histidine phosphotransfer (AHP) proteins (Hwang et al. 2012; Naseem et al. 2014; To et al. 2004, 2007). The activation of the cytokinin pathway results in the transcriptional expression of a set of specific cytokinin-regulated genes that have been identified by meta-analyses (Bhargava et al. 2013).

ARRs are encoded by a multigenic family comprising 21 members that have been classified in three types (A to C) depending on their structural domains and functions. Type A, comprising ARR3 to ARR9 and ARR15 to ARR17, negatively regulate cytokinin responses and members are transcriptionally regulated by type B ARRs. Type B, namely ARR1, ARR2, ARR10 to ARR14, and ARR18 to ARR21, are transcription factors that positively regulate cytokinin signaling (Hwang et al. 2012). A type $\mathrm{C}$ group of ARRs has also been described, but its role in cytokinin signaling is unclear (Horák et al. 2008; Kiba et al. 2004; Pils and Heyl 2009).

The activity of ARR members is, in general, partially redundant in the regulation of biological processes, and thus, even mutants impaired in six $A R R$ genes may still retain partial functions (To et al. 2004, 2007). Moreover, the existing regulatory loop between type A and type B ARRs could explain, at least in part, the observed contradictory functions of cytokinins in the regulation of some biological processes, like plant immune responses. For example, it has been suggested that type B ARRs might enhance immunity by promoting SA responses, whereas type A ARRs have been proposed to attenuate immune responses by inhibiting the SA pathway (Argueso et al. 2012; Naseem et al. 2015). Additionally, some ARRs, such as ARR2, ARR5, ARR7, and ARR15, can interact with ET signaling and modulate ET biosynthesis, which provides additional levels of regulation of immunity due to hormonal crosstalk (Hass et al. 2004; Shi et al. 2012).

Cytokinins have also been suggested to modulate plant cellwall structure by regulating the expression of genes encoding cell-wall remodeling proteins such as pectin-modifying enzymes, expansins, and laccases (Brenner et al. 2012). Furthermore, degradation of cytokinins has been linked to alterations in cell-wall integrity (CWI) that might function as a monitoring system to regulate developmental processes, such as cell cycle progression (Gigli-Bisceglia et al. 2018). Cytokinins also play important roles in vascular development and, for instance, ARR5 and ARR6 genes have been shown to regulate the formation of protoxylem vessels of the vascular system (Kondo et al. 2011). All these structural and biochemical cell-wall modifications regulated by cytokinins and ARRs might affect disease resistance responses and the in-planta spread of some pathogens, like vascular ones.

Activation of plant defensive responses requires the perception of signals that trigger specific resistance mechanisms through diverse molecular monitoring systems (Atkinson and Urwin 2012). Among these monitoring mechanisms are patterntriggered immunity (PTI) and effector-triggered immunity (Dodds and Rathjen 2010). PTI is based on the perception through pattern recognition receptors (PRR) of "non-self" microbe-associated molecular patterns (MAMPs), pathogen-associated molecular patterns, or "modified-self" damage-associated molecular patterns
(DAMPs) derived from the plant (Boller and Felix 2009; Boutrot and Zipfel 2017). MAMPs and DAMPs from different biochemical natures, i.e., proteins, carbohydrates, lipids, and nucleic acids, have been identified, thus reflecting the diversity of immunogenic structures recognized by plants (Boutrot and Zipfel 2017). Compared with MAMPs, far fewer DAMPs derived from plants have been identified to date (Bacete et al. 2018; Choi and Klessig 2016; Claverie et al. 2018; De Lorenzo et al. 2018).

An important source of DAMPs that is currently attracting research interest is the plant cell wall, which is a dynamic and highly regulated structure essential for plant growth and development. The functional integrity of cell walls is controlled by CWI monitoring systems (Engelsdorf and Hamann 2014; Engelsdorf et al. 2018). These systems trigger countervailing responses to cell-wall damage that occurs upon pathogen infection, abiotic stress, and cell expansion during growth and development (Vaahtera et al. 2019). The plant CWI pathway is strongly involved in the regulation of growth, immune responses, and resource allocation between development and immunity (Engelsdorf et al. 2018; Hamann et al. 2009; Wolf et al. 2012). Modification of cell-wall composition or integrity by genetic or chemical means might affect the capacity of some pathogens to degrade the wall during plant colonization and might lead to the activation of defensive signaling pathways, including those regulated by hormones (Bacete et al. 2018; Houston et al. 2016; Miedes et al. 2014; Nafisi et al. 2015). For example, enhanced resistance to pathogens has been observed in Arabidopsis mutants defective in cellulose synthases required for the biosynthesis of primary (prcl/ixrl/cev1, procuste1/ isoxaben resistant 1/constitutive expression of VSP1) or secondary (irx1/cesa8, irx3/cesa 7 and irx5/cesa4, from irregular xylem) cell walls (Ellis et al. 2002; Escudero et al. 2017; Hernández-Blanco et al. 2007). The disease-resistance phenotypes of irxl/irx3/irx 5 mutants are, in part, explained by the constitutive activation of the abscisic acid (ABA) pathway and the biosynthesis of antimicrobial compounds (Escudero et al. 2017; Hernández-Blanco et al. 2007). In contrast, prcl/ixrl/ cevl resistance phenotypes are associated with the activation of ET and JA signaling (Ellis et al. 2002). Similarly, the alteration of $O$-acetylation patterns from cell-wall xylans caused by mutations in ESKIMOI (ESK1) is associated with stressresistance phenotypes of eskl plants and an enhanced accumulation of ABA and strigolactones (Escudero et al. 2017; Lugan et al. 2009; Ramírez et al. 2018; Xin et al. 2007; Xu et al. 2014). In another example, the Arabidopsis walls are thin 1 (watl) mutant exhibits increased resistance to vascular pathogens, e.g., Ralstonia solanacearum, which is accompanied by higher SA levels and a general repression of indole metabolism (Denancé et al. 2013b). The alteration of the composition of wall pectins (e.g., degree of methylesterification) also affect disease-resistance responses, some of which can be reverted by auxins (Ferrari et al. 2008; Raiola et al. 2011). Also, cell-wall mutants with differential resistance to pathogens have been described whose immune responses are not associated with the activation of hormonal pathways (Delgado-Cerezo et al. 2012; Klopffleisch et al. 2011; Llorente et al. 2005; Raiola et al. 2011; Sánchez-Rodríguez et al. 2009).

Modifications of cell-wall structure or composition may also alter one or both the presence or release of cell wall-derived signaling molecules (e.g., DAMPs) that regulate immune responses. It has been shown that biochemical modification of the plant wall by cell wall-degrading enzymes secreted by pathogens during the colonization process can result in the release of DAMPs, such as pectic oligogalacturonides (OGs) derived from homogalacturonan (Benedetti et al. 2015; Lionetti et al. 2017; Ridley et al. 2001; Voxeur et al. 2019). Moreover, the 
overexpression or inactivation of plant genes encoding enzymes involved in the control of pectin structure (e.g., pectin methyl esterases [PMEs] and PME inhibitors) results in the modification of the degree of OG release upon infection and in disease-resistance phenotype alterations (De Lorenzo et al. 2018; Ferrari et al. 2008; Lionetti et al. 2017; Raiola et al. 2011). However, the relationship between composition or structure of the cell wall, the dynamic of the release of wall DAMPs, the activation of canonical defensive responses, and the resistance to pathogens are not well-understood.

Here, we show that arr6-3 plants defective in the ARR6 gene and ARR6 overexpression lines have altered and opposing disease-resistance outcome phenotypes to different pathogens. We also demonstrate that arr6-3 plants display alterations in the biochemical composition of their cell walls and that pectinenriched fractions extracted from arr6-3 walls contain wallrelated DAMPs triggering enhanced immune responses in comparison with pectin-enriched fractions extracted from wildtype plant walls. Our data demonstrate a novel link between the activity of regulatory components of the cytokinin pathway and Arabidopsis cell-wall composition and disease-resistance responses.

\section{RESULTS}

\section{$A R R 6$ modulates differential disease-resistance responses to pathogens.}

Arabidopsis mutants impaired in genes putatively involved in cell-wall biosynthesis or remodeling represent useful tools to study and characterize plant immunity mechanisms mediated by CWI (Bacete et al. 2018; Miedes et al. 2014). We selected the ARR6 gene to investigate the function of CWI on immunity, as this is the Arabidopsis ortholog of DV017520 from Zinnia elegans, a gene that is upregulated during late xylogenesis, which is a developmental process involved in secondary cellwall formation (Pesquet et al. 2005). ARR6 has also been described to regulate the formation of protoxylem vessels of the Arabidopsis vascular system and, accordingly, arr6 mutants show alterations in the xylem (Kondo et al. 2011). Moreover, data retrieved from the Bio-Analytic Resource for Plant Biology BAR ePlant database also indicated that ARR6 expression was repressed in wild-type Columbia-0 (Col-0) plants upon infection with different types of pathogens, like the vascular bacterium $R$. solanacearum (Hanemian et al. 2016; Hu et al. 2008) or the biotrophic oomycete Hyaloperonospora parasitica, after treatment with MAMPs (e.g., bacterial flg22 peptide) or under some abiotic stress conditions (Supplementary Fig. S1). Also, mutants impaired in several ARR members including ARR6 (e.g., arr5,6,8,9 and arr3,4,5,6,8,9 mutants) but not the single arr6-1 mutant have been described to show slightly enhanced resistance to $H$. parasitica (Argueso et al. 2012). Altogether, these data suggested that ARR6 could be associated with the modulation of cell-wall composition and activation of defense responses.

To further probe these putative ARR6 functions in the modulation of disease resistance and cell-wall composition, we selected for disease-resistance studies two T-DNA insertional alleles of ARR6 (arr6-2 and arr6-3) (Supplementary Fig. S2A). Quantitative real-time (qRT)-PCR analysis of ARR6 expression in the mutant alleles and Col-0 wild-type plants (Supplementary Fig. S2B) indicated that the arr6-3 allele was a knockout (null), whereas arr6-2 was a knockdown (hypomorphic) mutant. The arr6-2 allele harbors the T-DNA insertion very close to that present in arr6-1 allele, which was also previously described as a hypomorphic allele (To et al. 2004). The developmental phenotype of arr6 plants does not differ from that of wild-type plants, as previously described (To et al. 2004). We tested the disease-resistance phenotypes of arr6-2 and arr6-3 to pathogens with different lifestyles, namely, the necrotrophic fungus Plectosphaerella cucumerina BMM, the vascular bacterium $R$. solanacearum GMI1000, and the biotrophic oomycete $H$. parasitica Noco2. Notably, the arr6-3 mutant was slightly more resistant to the necrotrophic fungus $P$. cucumerina BMM than Col-0 wild-type plants, as determined by fungal biomass quantification by qPCR at 5 days postinoculation (dpi) and by disease rating (DR) determination at 7 dpi (Fig. 1A; Supplementary Fig. 3A). The accumulation of $P$. cucumerina BMM biomass and DR were slightly higher in arr6-3 than that observed in the irx 1-6 plants included as a resistant control, and in both mutants these values were significantly lower than that of Col-0 wild-type plants (Fig. 1A; Supplementary Fig. 3A). This contrasted with the enhanced fungal biomass and DR observed in the agbl-2 mutant, which was included as hypersusceptible control (Fig. 1A; Supplementary Fig. 3A) (Hernández-Blanco et al. 2007; Llorente et al. 2005). Remarkably, the arr6-3 mutant was highly susceptible to $R$. solanacearum GMI1000 and plants decayed at 10 to $12 \mathrm{dpi}$, as determined by visual evaluation of DR (Fig. 1B). As previously described for arr single mutants (Argueso et al. 2012), susceptibility to the oomycete $H$. parasitica of the arr6-3 allele was found to be similar to that of Col-0 plants, as determined by quantification of conidiosphores per milligram of fresh weight at 7 dpi (Fig. 1C). Similarly, the hypomorphic arr6-2 allele showed disease symptoms similar to those of Col-0 wild-type plants to the three pathogens tested (Supplementary Fig. S3B to D), which is in line with the previously described lack of differential phenotypes of arr6-1 hypomorphic allele (Argueso et al. 2012; To et al. 2004).

In view of the disease-resistance responses of the arr6-3 mutant and to corroborate the role of ARR6 in the modulation of these responses, we generated different Col- 0 lines that overexpress ARR6 (35S::ARR6) or ARR6 fused to the green fluorescence protein (GFP) or the human influenza hemagglutinin (HA) tags (35S::ARR6-GFP and 35S::ARR6-3HA) as well as plant lines overexpressing ARR6 in the arr6-3 background (arr6-3 35S::ARR6) (Supplementary Fig. S2C). ARR6 expression in these lines was evaluated by qRT-PCR and we selected, for further characterization, different overexpression lines (in Col-0 background) with expression levels of ARR6 transgenes four- to 10-fold higher than in Col-0 and arr6-3 lines (arr6-3 $35 S:: A R R 6)$ with ARR6 expression levels similar to that of wild-type plants (Supplementary Fig. S2B). Notably, in the arr6-3 35S::ARR6 lines tested the enhanced resistance to $P$. cucumerina BMM and susceptibility to $R$. solanacearum GMI1000 was almost restored to wild-type levels, further confirming the role of ARR6 in regulating these diseaseresistance responses (Fig. 1A and B; Supplementary Fig. S3A). In line with these results, we found that $P$. cucumerina BMM fungal growth $(5 \mathrm{dpi})$ and DR (7 dpi) in the $35 S:: A R R 6$ overexpression line were significantly increased compared with Col-0 plants, whereas $35 S:: A R R 6$ plants were more resistant to the bacterium $R$. solanacearum GMI1000 than Col-0 plants, as revealed by their delayed disease symptoms (Fig. 1A and B; Supplementary Fig. S3A). To further confirm these phenotypes associated to $A R R 6$ overexpression, independent overexpression lines (35S::ARR6-3HA and 35S::ARR6-GFP) were tested for disease resistance, and we found that they also showed enhanced susceptibility and resistance to $P$. cucumerina BMM and $R$. solanacearum GMI1000, respectively, as compared with Col-0 wild-type plants (Supplementary Fig. S3B and $\mathrm{C}$ ). In agreement with previous results (Argueso et al. 2012), the $35 S:: A R R 6$ lines tested were slightly more susceptible than Col-0 plants to the oomycete $H$. parasitica (Fig. 1C; Supplementary Fig. S3D). Altogether, these observations 

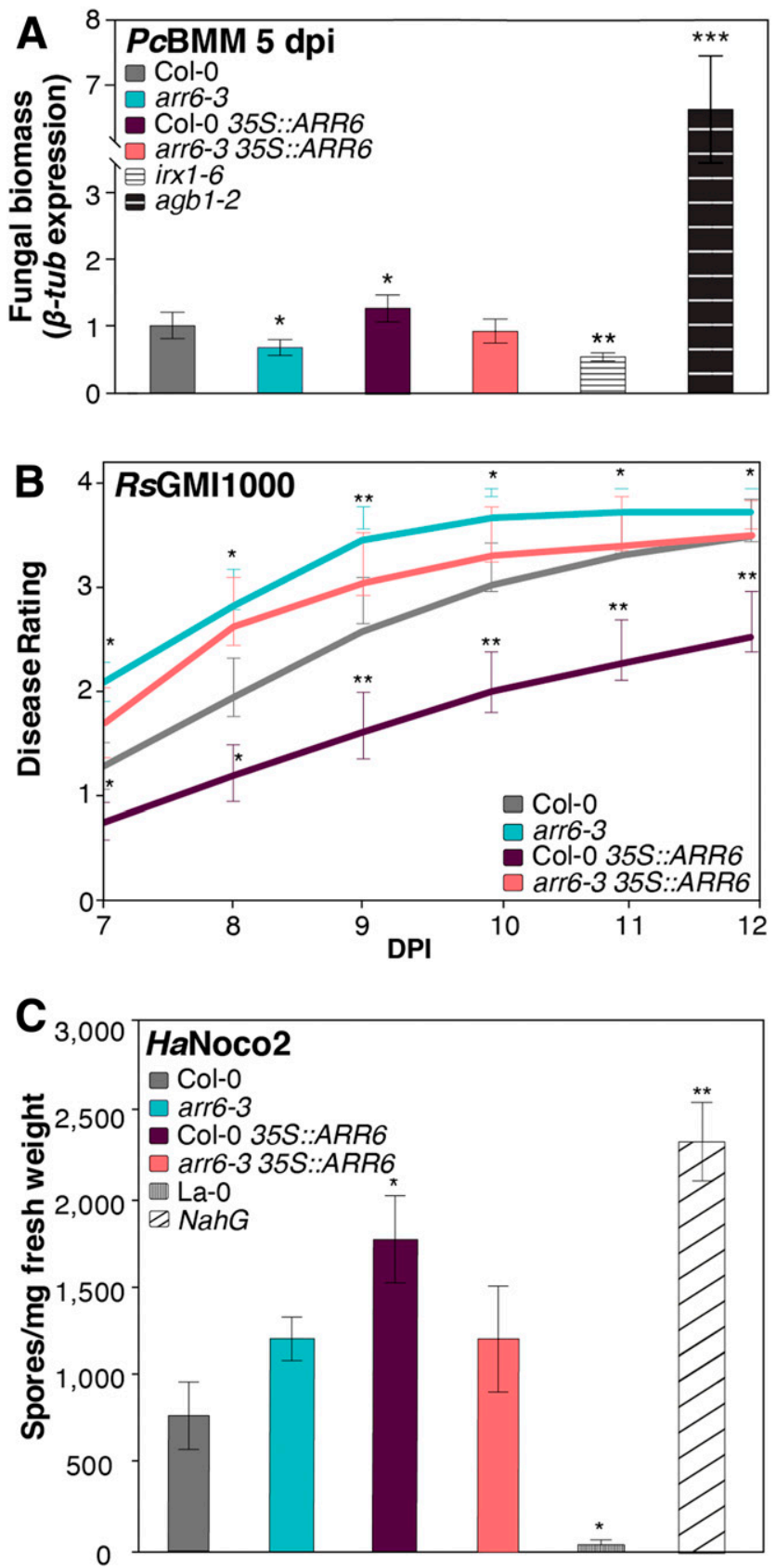

Fig. 1. Mutants and overexpression ARR6 lines display altered resistance to pathogens. A, Plectosphaerella cucumerina BMM biomass quantification by quantitative PCR of fungus $\beta$-tubulin ( $\beta$-tub) at 5 days postinoculation (dpi). Values are represented as the average ( \pm standard error [SE]) of the $n$ fold increased expression compared with Col-0 wild-type plants. Asterisks indicate statistically significant differences compared with the wild-type $\beta$-tub expression level (analysis of variance [ANOVA], multiple comparisons corrected by Holm-Sidak's test, one asterisk (*) indicates $P<0.05$, three (***) $P<0.001)$. Data are from one of three experiments performed $(n$ $=10)$ that gave similar results. B, Average disease index $( \pm \mathrm{SE})$, at different days postinoculation, of the indicated Arabidopsis genotypes inoculated with Ralstonia solanacearum GMI1000. Disease index: 0 (no symptoms) to 4 (100\% decayed plant). Asterisks indicate statistically significant differences compared with wild-type (Col-0) (ANOVA, multiple comparisons corrected by Holm-Sidak's test, one asterisk (*) indicates $P<0.05$, two (**) $P<0.01$, three $(* * *) P<0.001)$. Data are from one of two experiments performed with similar results. C, Disease resistance phenotypes upon infection with Hyaloperonospora arabidopsidis Noco2. Conidiospores per milligram of leaf fresh weight were measured at $7 \mathrm{dpi}$. Values are means of $n=20 \pm$ SE. Asterisks indicate statistically significant differences compared with wild-type (Col-0) (ANOVA, multiple comparisons corrected by Holm-Sidak's test, one asterisk (*) indicates $P<0.05$, two $(* *) P<0.01$ ). Data are from one of two experiments performed with similar results. support a novel function of ARR6 in the differential modulation of Arabidopsis resistance responses to $P$. cucumerina $\mathrm{BMM}$ and $R$. solanacearum GMI1000 and corroborate the redundant role of type A ARRs (including ARR6) in controlling the resistance to $H$. parasitica (Argueso et al. 2012).

arr6-3 plants show differential expression

of defense and cell wall-associated genes.

A comparative transcriptomic analysis of 18-day-old arr6-3 and Col-0 plants was performed. RNA was extracted from the plants 1 day after inoculation with $P$. cucumerina BMM or mock treatment. Microarray data analysis of mock-treated plants revealed 205 differentially expressed genes (DEGs) in arr6-3 compared with Col-0 plants, of which 153 and 53 were up- and down-regulated, respectively (Supplementary Table S1). Functional classification and Gene Ontology (GO) terms enrichment analyses performed using the hypergeometric test and Benjamini and Hochberg false discovery rate (FDR; corrected with a $P$ value cut-off of 0.05 ) indicated that $126 \mathrm{GOs}$ were over-represented among the DEGs (Fig. 2A; Supplementary Table S2). These GO included "Response to stimulus" $\left(\mathrm{GO}: 0050896, P\right.$ value $\left.=2.82 \times 10^{-5}\right)$ and "Regulation of transcription, DNA-templated" (GO:0006355, $P$ value $1.18 \times$ $\left.10^{-5}\right)$, each with 23 unique genes $(11.2 \%)$, and "Response to chitin" (GO:001020018, $P$ value of $3.09 \times 10^{-16}, 18$ genes representing 8.7\%) (Fig. 2A; Supplementary Table S2). A closer view of the "Response to stimulus" category revealed that most of the genes were related to defense responses (10 of 23 ) and response to stress (14 of 23), specifically, biotic stress (nine of 23) (Supplementary Table S2). In the case of the "Regulation of transcription, DNA-templated" category, we observed that a significant number of DEGs were related to the ET pathway (seven of 23). In addition, analysis of the 205 DEGs using the Thalemine web tool (Krishnakumar et al. 2017) indicated that the APETALA2/ethylene responsive factor (AP2/ ERF) domain (IPR001471) was over-represented $(P$ value $=5.71$ $\times 10^{-4}$ ) with 11 ERFs (5.34\% of DEGs) upregulated in arr6-3 (Supplementary Table S3). Among these ERFs, four belonged to the dehydration-responsive element binding (DREB) subfamily (group A), known to be involved in the regulation of dehydration- and cold-inducible genes (Sakuma et al. 2002), whereas seven were ERFs from group B (Sakuma et al. 2002) or IX (Nakano et al. 2006). Of note, six of these seven ERFs have been implicated in pathogen resistance (Nakano et al. 2006) and the majority of these ERFs were found to be upregulated in microarray data of Col-0 plants infected with either $P$. cucumerina BMM or $R$. solanacearum GMI1000 (Supplementary Fig. S4). These microarray values were validated in arr6-3 and Col-0 plants by qRT-PCR analysis of ARR6 and a set of genes selected based on their putative functional relevance in disease-resistance or abiotic-stress responses (Fig. 2B).

To determine if alteration of cytokinin perception contributes to arr6-3 disease-resistance phenotypes, we compared the arr6-3 DEGs with those of $a h k 1$ and ahk2 ahk3 mutants (EMEXP-1155) (Tran et al. 2007). Notably, only five DEGs were common between $a h k 2$ ahk3 and arr6-3 (including the downregulated ARRO) and one between ahkl and arr6-3 (Supplementary Fig. S5A). To strengthen these results, we also compared arr6-3 DEGs with the dataset of 75 cytokininspecific regulated genes proposed by Bhargava et al. (2013). In line with our previous comparison with $a h k 1$ and $a h k 2$ ahk3 datasets, we did not find any of these 75 cytokinin-responsive genes among the arr6-3 DEGs, further indicating that arr6-3 DEGs are not cytokinin-associated genes (Supplementary Fig. S5B).

We next studied the disease-resistance response of arr6-3 plants upon inoculation with $P$. cucumerina BMM, and we 
found 2,816 DEGs in arr6-3 inoculated plants, of which 905 were specifically expressed in arr6-3 but not in Col-0 (Fig. 2C; Supplementary Tables S5 and S6). According to GO term enrichment analysis, among these arr6-3 DEGs were genes related to defense responses, to diverse biotic and abiotic stresses, as well as to other physiological processes (Supplementary Fig. S6). Notably, among these 905 DEG, we found 75 of the 205 genes $(36.59 \%)$ constitutively upregulated in non-inoculated arr6-3 plants (Supplementary Fig. S5B; Supplementary Table S5), further supporting the function of this set of genes in disease-resistance responses. Strikingly, only nine of these arr6-3 DEGs upon P. cucumerina BMM infection were also among cytokinin-regulated marker genes described by Bhargava et al. (2013) (Supplementary Fig. S5). Together, these results
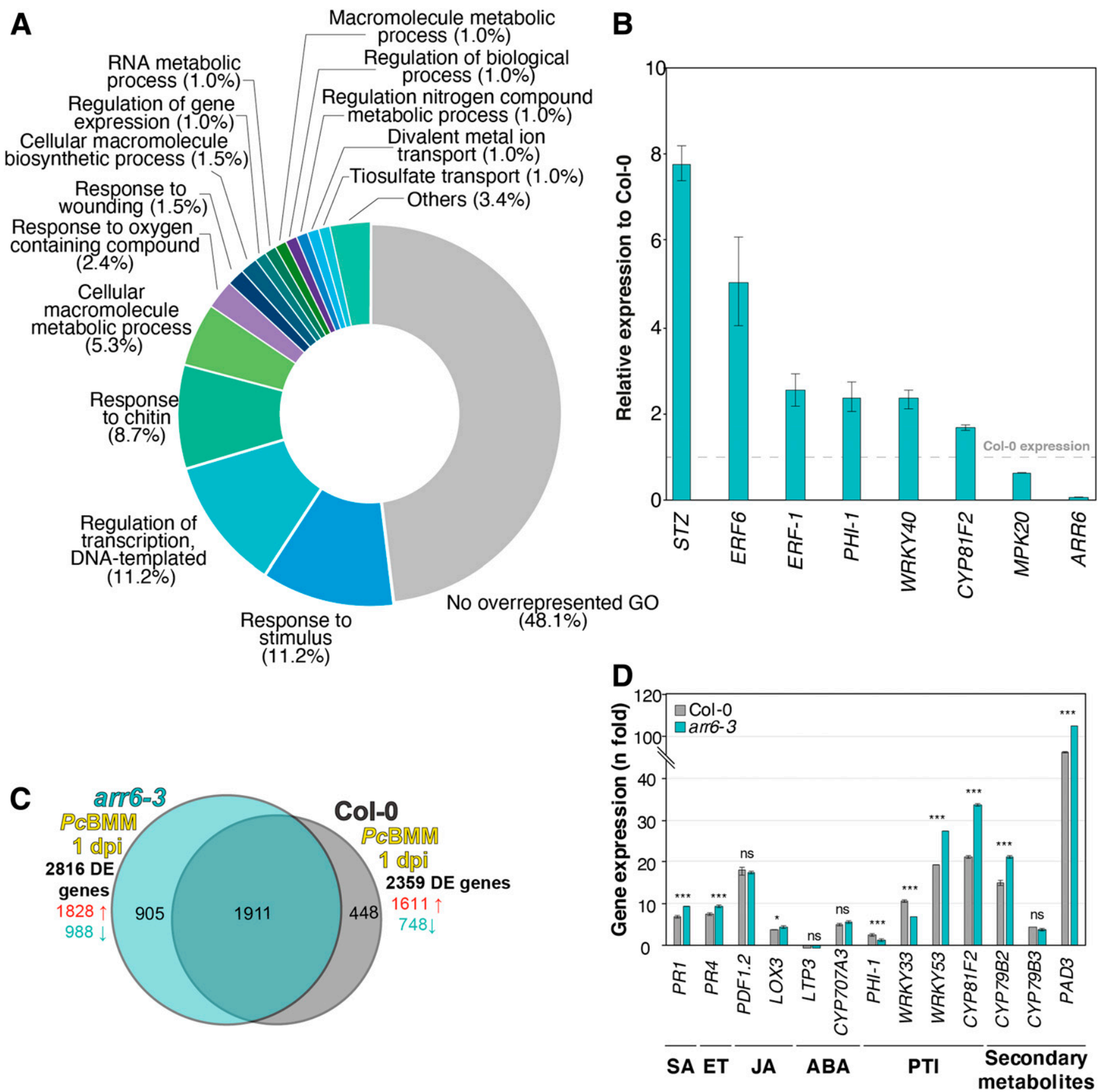

Fig. 2. Genes associated with response to stimuli are over-represented among arr6-3 differentially expressed genes (DEGs). A, Classification of the 205 DEGs in arr6-3 compared with wild type (Col-0). Biological function Gene Ontology (GO) terms over-represented among arr6-3 DEGs were determined using a hypergeometric test, the Benjamini and Hochberg false discovery rate (FDR), and a $P$ value cut-off of 0.05 . When a determined gene had more than one associated biological function GO term with a $P$ value $<0.05$, the GO term with lowest $P$ value was selected to classify that gene. B, Quantitative real-time (qRT)-PCR validation of arr6-3 DEGs identified. Values shown correspond to expression levels in arr6-3, calculated for each gene using $U B C 21$ (At5g25760) as a housekeeping gene, and are relativized to their expression level in Col-0. Mean values \pm standard error $(n=3)$ from a representative experiment of the three performed are represented. C, Venn diagram representing the DEGs in arr6-3 and wild-type (Col-0) plants at 1 day postinoculation (dpi) with the Plectosphaerella cucumerina BMM isolate. The number of DEGs is indicated for each treatment, indicating how many of these genes are upregulated (red upward pointing arrows) or downregulated (blue downward pointing arrows). D, Expression levels of genes implied in different defense-response pathways were determined by qRT-PCR in Col-0 and arr6-3 plants at 1 dpi with $P$. cucumerina BMM. Asterisks indicate statistically significant differences between Col-0 and arr6-3 (analysis of variance, multiple comparisons corrected by Dunnett's test, one asterisk (*) indicates $P<0.05$, two $(* *) P<0.01$, three $(* * *) P<0.001$. 
indicate that the arr6-3 disease-resistance phenotypes are unlikely to be associated with differential regulation of the cytokinin pathway.

Of note, canonical defense pathways (i.e., SA, ET, JA, and biosynthesis of secondary metabolites) and PTI signaling were up-regulated in response to $P$. cucumerina BMM infection both in Col-0 and arr6-3 plants, with a slightly higher upregulation in arr6-3 plants, as corroborated by qRT-PCR expression analysis of marker genes (Fig. 2D). These data suggested that the arr6-3 disease-resistance phenotypes are not associated to the misregulation of canonical defensive pathways. To further validate this hypothesis and to identify potential defenseassociated metabolites in arr6-3, we performed a comparative and global metabolite profiling of four-week-old, noninoculated arr6-3 and Col-0 plants. Within the 373 analyzed metabolites (including all the defensive hormones and some of
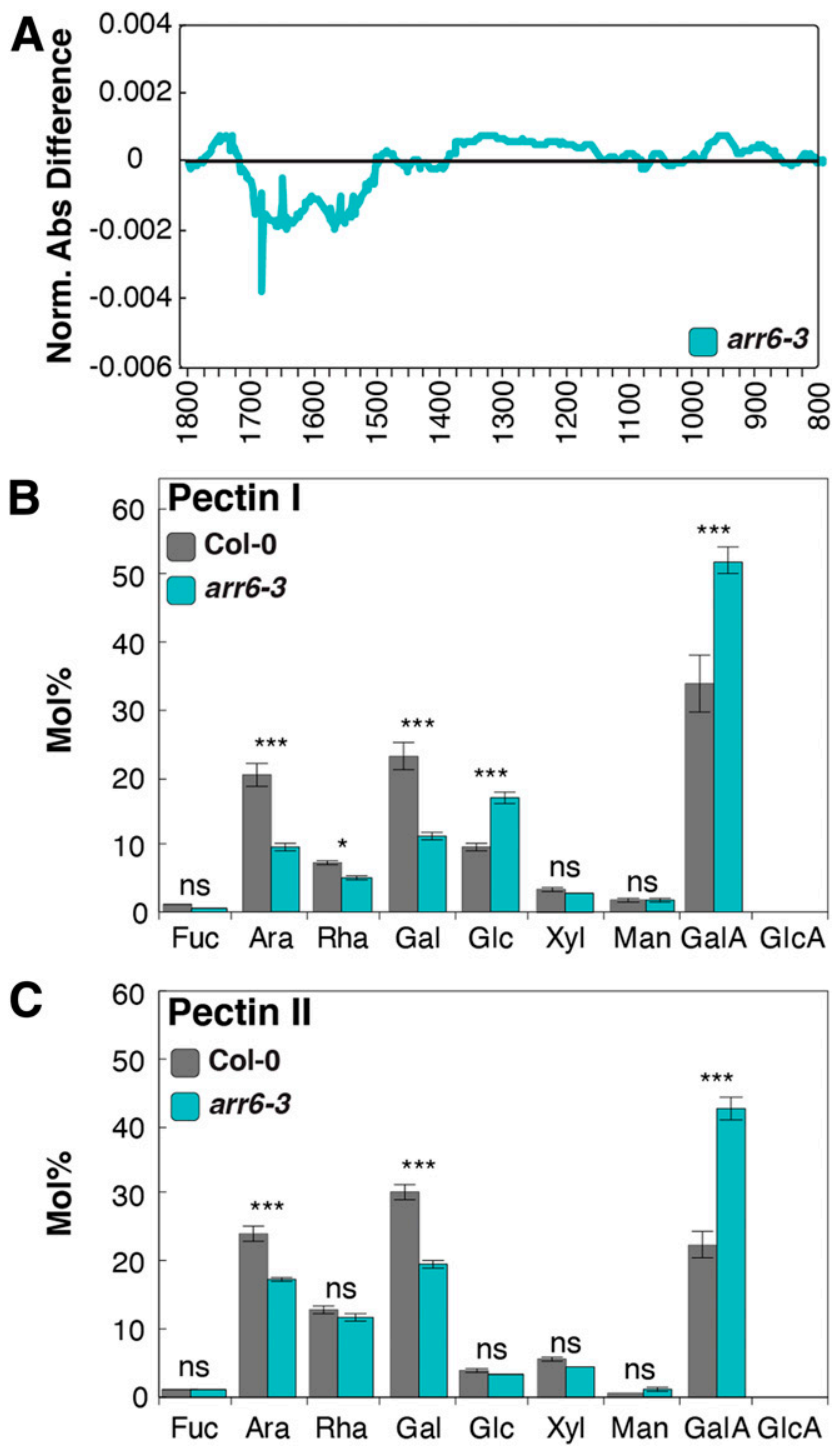

Fig. 3. arr6-3 plants display alterations in their cell-wall compositions. A Fourier-transform infrared spectroscopy difference spectra obtained after digital subtraction of Col-0 cell wall. $\mathbf{B}$ and $\mathbf{C}$, Monosaccharide composition (Mol\%) of pectin I (B) and pectin II (C) cell-wall fractions from Col0 wild-type and arr6-3 plants. Fuc $=$ fucose, Ara $=$ arabinose, Rha $=$ rhamnose, $\mathrm{Gal}=$ galactose, $\mathrm{Glc}=$ glucose, $\mathrm{Xyl}=$ xylose, Man $=$ mannose, $\mathrm{GalA}=$ galacturonic acid, GlcA = glucuronic acid. Asterisks indicate statistically significant differences (analysis of variance, multiple comparisons corrected by Holm-Sidak's test, one asterisk (*) indicates $P<0.05$, two (**) $P<0.01$, three $(* * *) P<0.001)$. their precursors), only 11 were more abundant ( $n$-fold higher than 1.5 and $P<0.1$ ) in arr6-3 compared with Col-0 (Supplementary Fig. S7A; Supplementary Table S7). Gentisate, a diseaseresistance modulator (Bellés et al. 2006; Návarová et al. 2012), and camalexin and sulforaphane-cysteine-glycine glucosinolate, two antimicrobial compounds (Buxdorf et al. 2013; Zhou et al. 1998), were found to be more abundant in the mutant than in Col-0 plants (Supplementary Fig. S7A; Supplementary Table S7). Glucosinolates but not camalexin have been previously shown to be required for Arabidopsis resistance to P. cucumerina BMM (Sánchez-Vallet et al. 2010). With the exception of cyano-alanine, a product of ET metabolism, which showed a slightly higher abundance in arr6-3, we did not find significant alterations in the levels of hormones or their precursors (e.g., SA, JA, and brassinosteroids) that regulate canonical immune pathways in arr6-3 plants (Supplementary Fig. S7B; Supplementary Table S7). The slight increased abundance of a small subset of antimicrobial compounds is, most likely, not sufficient to fully explain arr6-3 disease-resistance phenotypes to two different pathogens with distinct colonization styles.

Since some PTI marker genes (e.g., PHII) were up-regulated in non-inoculated arr6-3 plants (Fig. 2B) and showed a slightly enhanced expression upon $P$. cucumerina BMM infection, we determined PTI responses in arr6-3 plants upon treatment with two MAMPs (flg22 and chitin hexamer [Mélida et al. 2018]) and compared these responses with that of 35S:ARR6 and Col0 plants. The phosphorylation of mitogen-activated protein kinases (MAPKs: MAPK3, MAPK6, MAPK4, MAPK11) and expression of the PHI1 gene were slightly higher in arr6-3 than in Col-0 plants (Supplementary Fig. S8), which is in line with the transcriptomic data (Fig. 2B). Notably, MAPK phosphorylation was weaker in 35S:ARR6 plants than in Col-0, suggesting a defective activation of PTI in the overexpressor line (Supplementary Fig. S8). We then tested the expression of ARR6 in these genotypes, and we found that ARR6 expression was down-regulated upon MAMP treatment in Col-0, as described previously (Supplementary Fig. S1), but also in 35S:ARR6 plants. The results point to a complex mechanism of regulation of ARR6 function during immune activation.

\section{arr6 mutants show alterations} in their cell-wall composition.

Among the arr6-3 DEGs, we found 16 genes that were associated with one or both cell-wall biosynthesis and remodeling or with responses to CWI impairments (Supplementary Fig. S9), which suggested some cell-wall alterations in arr6-3 plants. Since ARR6 has been involved in regulation of formation of protoxylem vessels of the vascular system (Kondo et al. 2011), we determined the cell-wall composition of arr6-3 plants and compared it with that of wild-type plants. First, we performed a cell-wall characterization using Fourier-transform infrared (FTIR) spectroscopy to obtain 'cell wall fingerprints' that could reveal general differences between Col-0 and arr6-3 cell walls. FTIR is able to recognize polymers and functional groups and is used as a powerful and rapid technique for analyzing cell-wall components, since they can be assigned to different wavenumbers of the FTIR-spectra (Alonso-Simón et al. 2011). The analysis of the differential FTIR spectra obtained after digital subtraction of the wild-type values revealed differences mainly in the region between 1,500 and $1,750 \mathrm{~cm}^{-1}$ (Fig. 3A). This region is characterized by the absorption of uronic acids in wavenumbers 1,600 to 1,630 and $1,740 \mathrm{~cm}^{-1}$ (McCann et al. 1992; Mouille et al. 2003) and lignin at 1,515, 1,630, and 1,720 $\mathrm{cm}^{-1}$ (Séné et al. 1994; Carpita et al. 2001). With FTIR data pointing to differences in cell-wall components, such as uronic acids, lignin, or both, and bearing 
in mind that overlap in absorption and vibrational coupling between chemical bonds corresponding to different cell-wall polymers may occur, a more detailed biochemical characterization of the cell-wall composition was carried out.

We observed no quantitative difference in the amount of two major load-bearing cell-wall components such as lignin and cellulose between arr6-3 and Col-0 plants (Supplementary Fig. S9). In order to get a better understanding of the differences observed by FTIR, the highly complex cell-wall crude extracts
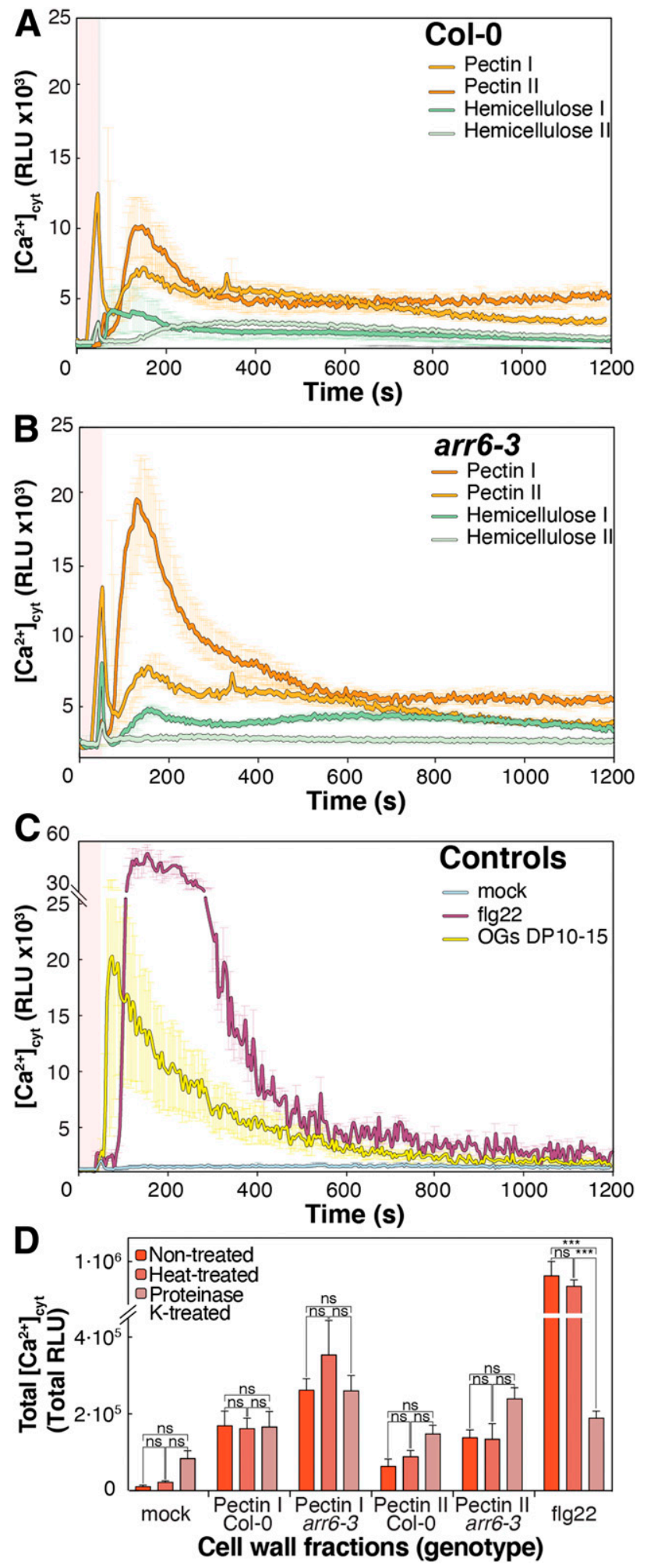

were chemically fractionated. Four fractions enriched in different cell-wall components (two pectic and two hemicellulosic ones) were analyzed for their monosaccharide composition and their glycosidic linkages types. arr6-3 pectin fractions displayed some striking differences in monosaccharides composition compared with their wild-type counterparts, whereas no significant differences in composition were found between their hemicellulose fractions (Fig. 3B and C; Supplementary Fig. $\mathrm{S} 10)$. In comparison with the Col-0 pectin I fraction, the arr6-3 fraction was highly enriched in galacturonic acid (57 versus $34 \mathrm{~mol} \%$ in Col-0) and glucose (17 versus $9 \mathrm{~mol} \%$ in Col-0), while they contained less arabinose, rhamnose, and galactose amounts than the fractions from wild-type plants (Fig. 3B). Similarly, the pectin II fraction from the mutant contained more galacturonic acid (45 versus $22 \mathrm{~mol} \%$ ) and lower arabinose and galactose content than that of Col-0 plants (Fig. 3C). Glycosidic linkage analyses of the pectin fractions confirmed that the enrichment in 1,4-linked galacturonic acid observed in the arr6 pectin fractions was from homogalacturonan-type polymers (Supplementary Fig. S11). Other 1,4-galacturonic acid-containing polymers such as rhamnogalacturonan did not show any increased levels of other residues from these structures, such as 1,2-linked rhamnose, ruling out the possibility that the observed increased levels in galacturonic were due to modifications in rhamnogalacturonan content (Supplementary Fig. S11). These analyses confirmed that arr6-3 cell walls are altered and that these modifications are mainly associated to the pectic fractions.

\section{The pectin-enriched fractions \\ from arr6 trigger immune responses.}

From the results presented above, we hypothesized that an enhanced and differential presence of carbohydrate-based DAMPs in the cell walls of arr6-3 in comparison with Col0 might explain, at least partially, the differential diseaseresistance responses of arr6-3 plants. These DAMPs, when released, would activate immune responses, thus triggering disease resistance. arr6-3 cell-wall fractions were tested for their capacity to trigger intracellular $\mathrm{Ca}^{2+}$ influxes, an early immune response, by using $\mathrm{Col}-0^{\mathrm{AEQ}}$ sensor lines that express the apoaequorin gene from Aequorea victoria and can be used as an in-vivo bioluminescent $\mathrm{Ca}^{2+}$ sensor (Knight et al. 1991; Mélida et al. 2018). Interestingly, we found that $\mathrm{Ca}^{2+}$ entry was activated by Col-0 and arr6-3 pectin fractions but not by hemicellulose ones. Moreover, arr6-3 pectin fractions induced

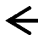

Fig. 4. Pectin-enriched cell-wall fractions trigger calcium influxes. A and $\mathbf{B}, \mathrm{Ca}^{2+}$ influx kinetics triggered in Col- $0^{\mathrm{AEQ}}$ seedlings by pectin I, pectin II, hemicellulose I, or hemicellulose II fractions from wild-type (Col-0) (A) or arr6-3 (B) plants (50 ng sugar/mL). C, Well-characterized damage- or pathogen-associated molecular patterns used as controls $(1 \mu \mathrm{M}$ flg22, $0.25 \mu \mathrm{M}$ oligogalacturonides with 10 to 15 degrees of polymerization [OGs DP 10-15], mock treatment is $\mathrm{H}_{2} \mathrm{O}$ ). All treatments were applied by automatic injection, and luminiscence was recorded in seconds, up to 1,200 s. Red-shaded areas represent time before automatic injection, i.e., background signal. Data shown in A to $\mathrm{C}$ belong to the same experiment but have been spliced into different panels. Values are means \pm standard error, $n=8$, and are representative of at least three biological replicates. $\mathbf{D}$, Variation of intracellular $\mathrm{Ca}^{2+}$ concentration after $10 \mathrm{~min}$ of treatment of Col- $0^{\text {AEQ }}$ seedlings with untreated pectin I fractions $(0.5 \mu \mathrm{g} / \mu \mathrm{l})$ or flg22 $(500 \mathrm{nM})$ or fractions treated with heat $\left(20 \mathrm{~min}\right.$ at $\left.95^{\circ} \mathrm{C}\right)$ or proteinase $\mathrm{K}(1$ $\mathrm{U}$ overnight at $37^{\circ} \mathrm{C}$ ) followed by heat treatment for $20 \mathrm{~min}$ at $95^{\circ} \mathrm{C}$. Bars indicate significant differences between $\mathrm{Ca}^{2+}$ influx triggered by fractions subjected to different treatments (analysis of variance, multiple comparisons corrected by Holm-Sidak's test, three asterisks (***) indicate $P<$ 0.001). Proteinase $\mathrm{K}$ might have an effect on plants or growth medium used, since we observed an increase in $\mathrm{Ca}^{2+}$ concentration in mock samples $\left(\mathrm{H}_{2} \mathrm{O}+\right.$ proteinase $\left.\mathrm{K}\right)$ upon application to seedlings. 
higher $\mathrm{Ca}^{2+}$ influxes than those from Col-0 (Fig. 4A). These calcium signatures were compatible with a ligand-receptor binding interaction, like that observed for flg22 MAMP and $\mathrm{OG}_{10-15}$ (degree of polymerization [DP] of 10-15) DAMP, which were included in the experiment as controls (Fig. 4A). Of note, the DAMPs contained in pectin I and pectin II fractions from Col-0 and arr6-3 remained active (e.g., triggered $\left[\mathrm{Ca}^{2+}\right]_{\mathrm{cyt}}$ entry) after different treatments affecting stability of proteins, i.e., denaturation by heat treatment and proteolysis with proteinase K combined with heat denaturation (Fig. 4B). Slight but not significant increases in the activity of these fractions were observed in some cases upon these treatments (Fig. 4B) that are consistent with solubilization effects of the fractions, which would facilitate the release of their DAMPs, as it has been previously reported for insoluble polysaccharides subjected to heat solubilization (Mélida et al. 2018). Such observation contrasted with the immune activity of flg22 after heat + proteinase $\mathrm{K}$ treatment that was significantly reduced (Fig. 4B). The resistance to proteolysis of the pectin I fraction from arr6-3 and Col-0 suggested that this fraction contains DAMPs that are not peptides and might be of glycosidic nature.

The pectin-enriched fractions extracted from arr6-3 and Col0 cell walls triggered phosphorylation of MAPK3 and MAPK6 but not MAPK4 or MAPK11 in Col-0 wild-type plants, since the activities of pectin I fractions were higher than those of pectin II (Fig. 5A and B). The pectin I-induced MAPK phosphorylation was similar to that triggered by $\mathrm{OG}_{10-15}$, since no phosphorylation of MAPK4 or MAPK11 occurred, in contrast to the phosphorylation triggered by flg22 (Fig. 5C). We also evaluated the expression of PTI marker genes in wild-type plants $30 \mathrm{~min}$ after treatments with pectin fractions from Col-0 and arr6-3 plants or water. The selected genes for the qRT-PCR analyses were either specifically activated by the calciumdependent protein kinase (CDPK) pathway (i.e., PHI-1, which is constitutively up-regulated in arr6-3), the CDPKs + MAPKs pathways (i.e., $C Y P 81 F 2$ ), or by pathogens (e.g., WRKY33 [Boudsocq and Sheen 2013; Boudsocq et al. 2010]). Remarkably, upregulation of these three genes was observed in Col-0 plants treated with the arr6-3 pectin fractions (Fig. 5D and E) and such induction was comparable to that observed upon treatments with highly purified MAMPs or DAMPs, such as flg22 or $\mathrm{OG}_{10-15}$ (Fig. 5F). Of note, Col-0 pectin I fractions did not trigger the expression of any of these marker genes upregulated by the arr6-3 pectin I fraction (Fig. 5D and E), whereas the pectin II fractions from arr6-3 and Col-0 plants induced similar expression of the tested genes (Fig. 5D and E). Together these data suggested that the arr6-3 pectin I fraction contained either enhanced levels of DAMPs compared with the Col-0 fraction or specific DAMPs, of glycosidic nature, that triggered differential immune responses.

\section{DISCUSSION}

The plant cell wall is currently viewed as a dynamic structure regulating different processes, like immunity and development (Bacete et al. 2018; Bethke et al. 2016; De Lorenzo et al. 2018 Engelsdorf et al. 2018; Voxeur and Höfte 2016). To better understand the relationship between plant cell walls and immunity, we have characterized the function of the Arabidopsis ARR6 gene in the regulation of CWI and disease-resistance responses. This gene was selected based on: i) its expression profile in Arabidopsis plants subjected to different stresses, including MAMP treatment (Supplementary Figs. S1 and S8); ii) its described role on protoxylem vessel formation (Kondo et al. 2011); iii) the upregulation of its Zinnia elegans ortholog during xylogenesis, a secondary cell-wall biosynthetic process triggered by auxin and cytokinin (Pesquet et al. 2005); and iv) its expression during $R$. solanacearum infections, since ARR6 expression is repressed in leaves from susceptible Arabidopsis genotypes but is up-regulated in clavatal mutants that are more
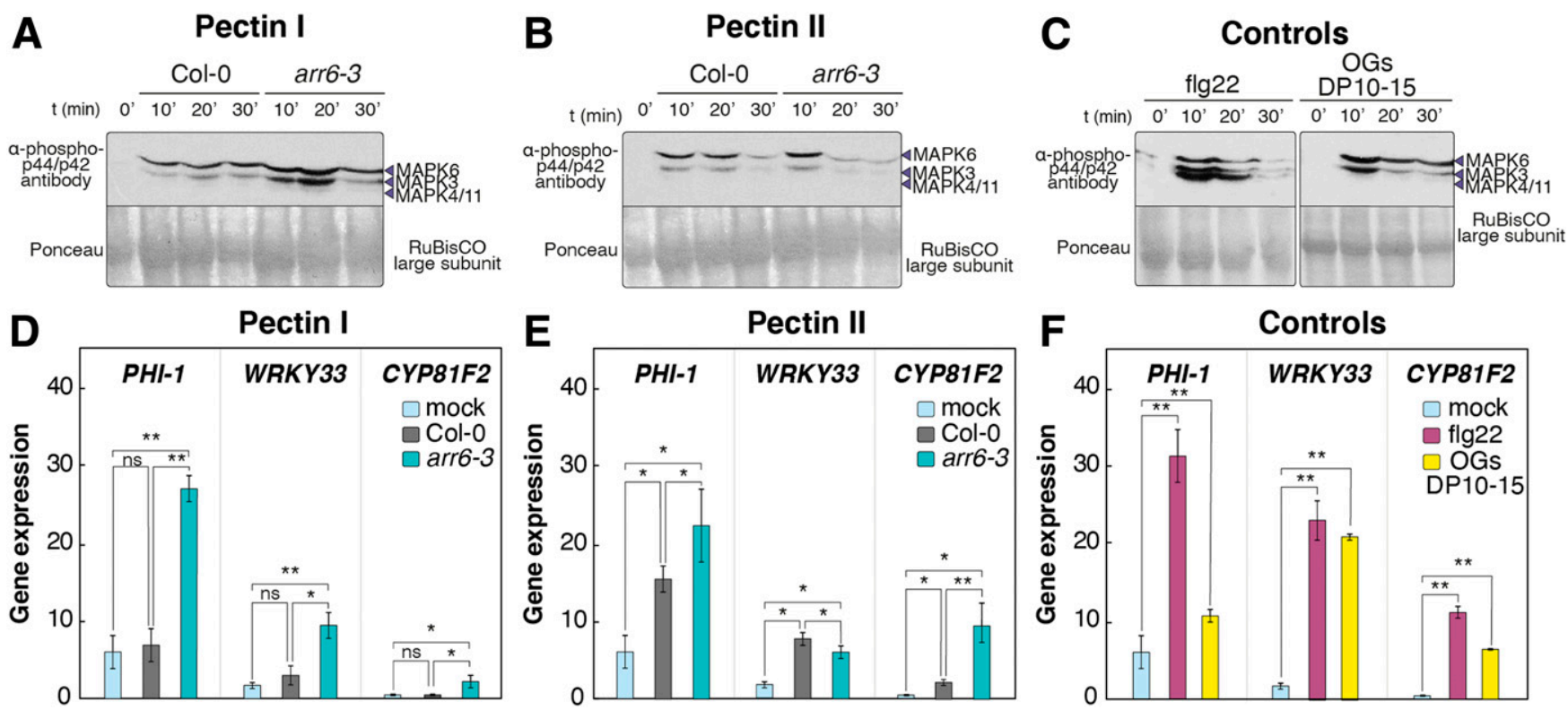

Fig. 5. Activation of pattern-triggered immunity responses by pectin cell-wall fractions from Col- 0 and the arr6-3 mutant. A to C, Western blot determination of mitogen-activated protein kinase (MAPK) phosphorylation at different timepoints (0, 10, 20, and 30 min) upon application to wild-type plants (Col-0) of the pectin I or B, pectin II fractions from Col-0 or arr6 plants $(0.5 \mu \mathrm{g} / \mu \mathrm{l})$ or $\mathbf{C}, 100 \mathrm{nM}$ flg22 and $0.5 \mu \mathrm{g}$ of the $\mathrm{OG}_{10-15}$ control per microliter (oligogalacturonides with 10 to 15 degrees of polymerization [OGs DP 10-15]). $\alpha$-Phospho-p44/42 rabbit antibody was used for MAPK detection, and Ponceau staining was used to show equal protein loading. Data are representative of one of three independent experiments performed with similar results. All these samples were analyzed in the same experiment and blot. D, Quantitative real-time PCR analyses of defense and microbe-associated molecular pattern-induced genes in Col-0 seedlings treated for 30 min with pectin I or $\mathbf{E}$, pectin II fractions $(0.5 \mu \mathrm{g} / \mu \mathrm{l})$ or $\mathbf{F}, 100 \mathrm{nM}$ flg 22 and $0.5 \mu \mathrm{g}$ of $\mathrm{OG}_{10-15}$ per microliter. Relative expression levels to the UBC21 (At5g25760) gene are shown. Asterisks indicate significant differences (analysis of variance, multiple comparisons corrected by Dunnett's test, one asterisk (*) $P<0.05$, two $(* *) P<0.01$ ). Data are representative of one of two independent experiments performed with similar results. 
tolerant to this bacterium than wild-type plants (Hanemian et al. 2016; Hu et al. 2008). These data suggest that ARR6 could be involved in the regulation of stress responses or modulation of plant cell-wall composition or both. In line with this initial hypothesis, we have demonstrated that, compared with wildtype plants, the arr6-3 loss of function mutant allele shows differential disease-resistance phenotypes to different pathogens (Fig. 1; Supplementary Fig. S3) and alterations in its cellwall composition (Fig. 3).

ARR6 belongs to type A ARRs, which have been previously described to be involved in disease resistance. For example, an arr 3,4,5,6,8,9 sextuple mutant exhibited decreased susceptibility to the biotrophic pathogen $H$. parasitica, whereas transgenic lines overexpressing either ARR6, ARR5, or ARR9 were more susceptible to this pathogen (Argueso et al. 2012). The unaltered resistance phenotype of the arr6-3 single mutant to $H$. parasitica (Fig. 1) compared with the described enhanced resistance of the arr3,4,5,6,8,9 mutant indicates that ARR6 has overlapping functions with other ARRs in the regulation of disease-resistance responses to $H$. parasitica, as previously reported (Argueso et al. 2012). Notably, we have shown that arr6-3 is more resistant and susceptible, respectively, than Col0 plants to the necrotrophic fungus $P$. cucumerina and to the vascular bacterium $R$. solanacearum (Fig. 1; Supplementary Fig. S3), further supporting a relevant and specific function of ARR6 in the regulation of disease-resistance responses to these two pathogens with different lifestyles. As previously described for arr6-1 (To et al. 2004), the additional hypomorphic allele (arr6-2) tested here did not show any alteration on the diseaseresistance phenotypes tested (Supplementary Fig. S3). Interestingly, ARR6 expression is down-regulated by MAMPs (e.g., flg22) and different biotroph and necrotroph pathogens, in both compatible and incompatible interactions (Supplementary Figs. S1 and S8). This highlights the relevance of ARR6 in the immune response and suggests that ARR6 may act as a negative regulator of disease-resistance activation against certain pathogens (e.g., P. cucumerina BMM) similarly to what has been described for other genes, such as PMR6, that mediate cell wall-based resistance to pathogens (Vogel et al. 2002). The specific function of $A R R 6$ in immunity was further supported by the disease phenotypes of lines overexpressing ARR6, which showed opposite disease-resistance phenotypes to arr6-3 (e.g., in 35S::ARR6, 35S::ARR6-GFP, and 35S::ARR6-HA) or complemented them (e.g., arr6-3 35S::ARR6 lines) (Fig. 1; Supplementary Fig. S3). Notably, ARR6 expression was downregulated in 35S::ARR6 plants upon treatment with MAMPs, suggesting a complex regulation of ARR6 function during PTI activation (Supplementary Fig. S8C). Together, these results corroborate a role of type A ARRs in the regulation of disease-resistance responses and support a relevant function of ARR6 in this process.

Cytokinins have been suggested to upregulate plant immunity via an elevation of SA-dependent defense responses that, in turn, inhibit cytokinin signaling in a feedback loop (Argueso et al. 2012). Type-A ARRs are considered central components of this process and of other hormonal cross-talks (e.g., cytokinin-ET) that are activated in response to different stresses (O'Brien and Benková 2013; Shi et al. 2012). These regulatory pathways are mediated by the cytokinin receptors AHK2 and AHK3, which function upstream of ARRs (including ARR6) sensing cytokinin concentrations (Argueso et al. 2012; Hwang and Sheen 2001). However, the transcriptome pattern of $a h k 2$ ahk3 double mutants did not overlap with that of arr6-3 and neither did that of the ahkl mutant (Supplementary Fig. S5A), which is impaired in the CWI sensor AHK1 (Hamann et al. 2009; Wormit et al. 2012). Therefore, AHK1, AHK2, and AHK3 do not seem to be linked, at least at the transcriptional level, with the alterations in gene expression observed in the arr6-3 plants, suggesting that the immune responses regulated in arr6-3 are not related to the cytokinin signaling pathway or, at least, with AHK2 and AHK3 function. This is further supported by the fact that none of the cytokinin-regulated genes identified in previous works (Bhargava et al. 2013) are among the DEGs in arr6-3 mock-treated plants and only nine of the arr6-3 DEGs upon $P$. cucumerina BMM infection were among the set of cytokinin-regulated marker genes (Bhargava et al. 2013) (Supplementary Fig. 5B). Similarly, metabolomic and transcriptomic analyses of arr6-3 plants demonstrated that canonical immune pathways, like those regulated by hormones, are not misregulated in the arr6-3 in comparison with wild-type plants, since hormone homeostasis and expression of marker genes of the pathways mediated by these hormones are not altered in the mutant (Fig. 2; Supplementary Tables S4 and S7).

Transcriptomic analyses of arr6-3 plants identified defenseassociated genes that are specifically up-regulated in noninoculated and $P$. cucumerina BMM-infected plants (Fig. 2; Supplementary Fig. 6; Supplementary Tables S4 and S5) and that may help explain arr6-3 resistance to this fungus. For example, arr6-3 plants are characterized by a clear overrepresentation of upregulated genes encoding ERF transcriptional factors belonging to group IX-b, whose members are known to be involved in responses to pathogens (Licausi et al. 2013). Transgenic lines overexpressing ERF5 or ERF6 are resistant to the necrotrophic fungus Botrytis cinerea but show enhanced susceptibility to Pseudomonas syringae pv. tomato DC3000 (Huang et al. 2016; Moffat et al. 2012; Wang et al. 2013), ERF104 overexpression lines are resistant to $P$. syringae pv. phaseolicola (Bethke et al. 2009), and overexpression of ERF1 confers enhanced resistance to the necrotrophic fungi $P$. cucumerina and B. cinerea (Berrocal-Lobo et al. 2002). Thus, the observed enhanced resistance of arr6-3 to $P$. cucumerina BMM could be explained, at least in part, by the expression pattern of some ERF genes. Additionally, the enhanced accumulation of some antimicrobial secondary metabolites in arr63 (Supplementary Fig. S7) may also contribute to arr6-3 disease resistance (Sánchez-Vallet et al. 2010). Moreover, some PTI responses (e.g., phosphorylation of MAPKs) are enhanced in arr6-3 upon MAMP treatment in comparison with wild-type plants (Supplementary Fig. S8A and B), suggesting a negative function of ARR6 in immune regulation. In line with this function, ARR6 expression was down-regulated upon pathogen infection and MAMP treatment (Supplementary Figs. S1 and $\mathrm{S} 8$ ).

Arabidopsis resistance to $R$. solanacearum has been shown to be enhanced in ET signaling mutants (Hirsch et al. 2002), indicating that ET has a negative regulatory role on Arabidopsis resistance response to this bacterium, which is in line with the finding that ET is one of the effectors produced by $R$. solanacearum to colonize Arabidopsis (Weingart et al. 1999). The constitutive upregulation in arr6-3 plants of some $E R F s$, regulated by the ET pathway, as well as other genes that are DEGs in susceptible Arabidopsis-R. solanacearum interactions might explain the enhanced susceptibility of arr6-3 to the bacterium (Hanemian et al. 2016; Hu et al. 2008). Notably, ARR6 expression is repressed in leaves from susceptible plants compared with resistant plants during $R$. solanacearum infections and is activated in clavatal mutants that are more tolerant to this bacterium than wild-type plants (Hanemian et al. 2016; $\mathrm{Hu}$ et al. 2008). Also, the alteration of protoxylem vessel structure in arr6-3 plants might help to explain the enhanced susceptibility of arr6-3 to the vascular bacterium that systemically colonize the plant through the xylem (Hirsch et al. 2002). All these $R$. solanacearum-associated susceptibility factors of arr6-3 plants might favor bacterial colonization and are not 
counterbalanced by the slight enhanced activation of PTI observed in the arr6-3 or the higher PTI activity of the DAMPs found in mutant wall fractions in comparison with Col0 fractions.

Here, using biochemical analyses, we show that leaves of arr6-3 plants display significant alterations in their cell-wall composition, particularly in their pectic fractions (Fig. 3), which is in line with the described alteration of protoxylem vessel formation in a different arr6 allele (Kondo et al. 2011). These arr6 cell-wall features may contribute to the differential disease-resistance responses of arr6 plants as the cell-wall structure influences Arabidopsis resistance to $R$. solanacearum and $P$. cucumerina, as observed in irx 1 , esk 1 , and wat 1 mutants (Denancé et al. 2013b; Digonnet et al. 2012; Escudero et al. 2017; Hernández-Blanco et al. 2007), and pectins have been described as being involved in Arabidopsis resistance to necrotrophic fungi, like $B$. cinerea (Bethke et al. 2016; Lionetti et al. 2017). Beyond structural reasons, pectins - homogalacturonan in particular-are a source of different types of OGs, the bestcharacterized plant cell wall-derived DAMPs, which regulate DAMP-triggered immunity (Davidsson et al. 2017; Ferrari et al. 2013; Galletti et al. 2008; Voxeur et al. 2019).

The increased abundance of homogalacturonan in the arr6-3 pectic fractions suggested that some OGs, or the OG concentration or availability of OGs might be higher in arr6-3 walls than in wild-type ones and, accordingly, we found that the pectin I and pectin II fractions from arr6-3 mutant triggered enhanced immune responses in Arabidopsis Col-0 plants, in comparison with the responses activated by the corresponding fractions from wild-type plants (Figs. 4 and 5). These data suggest that additional or higher concentrations of DAMPs are present in arr6 wall fractions compared with Col-0 fractions. Also, we can hypothesize that differential release of specific DAMPs might occur upon infection of arr6-3 and Col-0 plants by distinct pathogens expressing different sets of cell walldegrading enzymes. Interestingly, the arr6-3 pectin I fraction but not that of Col-0 plants triggers the upregulation of some marker genes (e.g., PHI-1) that are also constitutively upregulated in arr6-3 plants, suggesting that some of these genes would be markers of immune responses activated by the arr6 pectin I fraction. We also show here that MAPK phosphorylation cascades, which have a crucial role in signal transduction in response to pathogens (Meng and Zhang 2013) and regulate immune responses, are triggered by the pectin I and pectin II fractions of arr6-3 and Col-0 plants. Phosphorylation patterns upon treatment with pectin I or pectin II fractions or $\mathrm{OG}_{10-15}$ support the idea that the pathways activated by these fractions are not identical to those activated by flg22 (Fig. 5). Based on the enhanced PTI-triggering capacities of arr6-3 pectic fractions, their direct application to plant leaves should confer disease resistance. However, future research will be needed in this direction in order to get suitable formulations of these complex carbohydrate mixtures that will favor penetration of DAMPs through the plant cuticle and will avoid their degradation by epiphytic microorganisms or pathogens in leaves, as has been described previously (Trouvelot et al. 2014).

In summary, we show here that impairment of the ARR6 gene affects cell-wall composition, which may impact plantpathogen interactions and lead to the accumulation of precursors of the differential DAMPs (e.g., OGs) that would favor a "defense-ready" state instead of resting stage. Under the attack of a necrotrophic pathogen harboring a repertoire of cell wall-degrading enzymes, these DAMPs would be released and perceived through unidentified PRR complexes, contributing to the observed increased resistance of arr6-3 plants. However, this response would not take place in arr6-3 plants being attacked by pathogens that colonize the plant through the vascular system but that do not massively degrade plant cell walls, such as $R$. solanacearum GMI1000. Further characterization of ARR6-mediated immunity will pave the way to understand its role in CWI perception and maintenance and PTI regulation.

\section{MATERIALS AND METHODS}

\section{Plant material and growth conditions.}

The Arabidopsis thaliana mutants used in this work, i.e., arr6-2 (SALK_008866) and arr6-3 (SALK_133123), were in Col-0 genetic background. Details of all mutant lines are provided in Supplementary Table S8. Arabidopsis plants were grown as previously described (Mélida et al. 2018; Sánchez-Vallet et al. 2010). For generation of ARR6 transgenic lines, constructs (Supplementary Fig. S1) were brought into the Agrobacterium tumefaciens C58 strain using Gateway technology (Earley et al. 2006). ARR6 (At5g62920) cDNA was cloned in Gateway plasmids $p G W B 2, p G W B 5$, and $p G W B 14$. The constructs were used to transform wild-type Col-0 and arr6-3 plants by the standard floral dip method (Clough and Bent 1998). Segregation was analyzed until the T4 generation on one-half MurashigeSkoog $1 \%$ sucrose agar plates containing $50 \mu \mathrm{g}$ of hygromycin per liter. For each combination of background and construct, expression levels of 10 independent transgenic lines were analyzed by qRT-PCR using oligonucleotide primers (Supplementary Table S9). Two lines from each construct with different expression levels of the transgene were selected for further analyses and one of them was tested for resistance (Fig. 1; Supplementary Figs. S2 and S3; data not shown).

\section{Pathogenicity assays.}

For P. cucumerina BMM pathogenicity assays, 18-day-old plants $(n>12)$ growing on soil were sprayed with a spore suspension $\left(4 \times 10^{6}\right.$ spores per milliliter) of the fungus, as previously described (Delgado-Cerezo et al. 2012; SánchezVallet et al. 2010). Fungal biomass in planta was quantified at 5 dpi by qPCR determining the $\beta$-tubulin gene from the fungus and normalizing these values to those of the $U B C 21$ (At5g25760) gene from Arabidopsis thaliana (Delgado-Cerezo et al. 2012). The progress of $P$. cucumerina BMM infection was estimated at $7 \mathrm{dpi}$ as average DR from 0 to 5 , where $0=$ no symptoms, $1=$ plant with some necrotic spots, $2=$ one or two necrotic leaves, $3=$ three or more leaves showing necrosis, $4=$ more than half of the plant showing profuse necrosis, and $5=$ decayed or dead plant (Delgado-Cerezo et al. 2012). For Hyaloperonospora arabidopsidis Noco2 assays, 12-day-old plants $(n>20)$ were sprayed with a conidiospore suspension $\left(2 \times 10^{4}\right.$ spores per milliliter). Plants were incubated under short-day conditions for 7 days, the aerial parts of all plants were harvested, and released conidiospores were counted (Mélida et al. 2018). A bacterial suspension of $R$. solanacearum GMI1000, cells grown as described by Deslandes et al. (1998), were used for root inoculation of 28-day-old plants and bacterial growth curves were then calculated by determining the disease index (from 0 [no symptoms] to 4 [100\% wilted leaves or dead plant]) of inoculated plants, as described previously (Deslandes et al. 1998).

\section{Transcriptomic analyses.}

For transcriptomic analyses, 18-day-old wild-type and arr6-3 plants were mock-treated or $P$. cucumerina BMM-inoculated and rosettes $(n>25)$ were collected at $1 \mathrm{dpi}$ (four biological replicates). Total RNA was extracted, using the RNeasy mini kit (Qiagen), and was resuspended in $30 \mu \mathrm{l}$ of RNase-free water. RNA quality was tested using a Bioanalyzer 2100 (Agilent Technologies). The one-color microarray-based gene expression 
analysis protocol (Agilent Technologies) was used to amplify and label RNA with cyanine-3-labeled CTP (Cy3). Three of the four biological replicates were independently hybridized for transcriptomic comparison, using Arabidopsis (V4) gene expression microarrays 49 44k (G2519F; Agilent Technologies). The expression levels of the genes were visualized with the FIESTA Viewer (BioinfoGP, Spanish National Biotechnology Centre (CNB)-CSIC). Differentially expressed genes were selected based on i) fold change, which had to be $<2$ or $>2$, and ii) $P$ value, calculated with the LIMMA package, which had to be $<0.05$. The expression of some genes identified in the transcriptome analysis was validated by qRT-PCR amplification, using the oligonucleotides listed in Supplementary Table S9.

\section{Cell-wall fractionation and characterization.}

Plant material was collected and was immediately frozen in liquid nitrogen. Cell walls and their fractions were prepared as described (Bacete et al. 2017). FTIR spectroscopy determination was done with discs prepared from mixtures of purified AIR and $\operatorname{KBr}(1: 100$, wt/wt), using a Graseby-Specac press. FTIR spectra were recorded and analyzed as described (Mélida et al. 2009). Lignin-like material was quantified by the Klason gravimetric method with minor modifications (Mélida et al. 2015a). Cell-wall extracts were hydrolyzed with $72 \%$ (wt/vol) sulphuric acid for $1 \mathrm{~h}$ at $30^{\circ} \mathrm{C}$. Sulphuric acid was subsequently diluted to $2.5 \%$ (wt/vol) with water and the mixtures were further heated at $115^{\circ} \mathrm{C}$ for $1 \mathrm{~h}$. The residues were filtrated through Durapore polyvinylidene diflouride filters $(0.45 \mu \mathrm{m}$; Millipore $)$, were dried, and were weighed. Cellulose quantifications were performed as previously described (Sopeña-Torres et al. 2018).

For monosaccharide analysis, dried purified cell-wall fractions $(0.5 \mathrm{mg})$ were hydrolyzed in the presence of $2 \mathrm{M}$ trifluoroacetic acid (TFA) at $121^{\circ} \mathrm{C}$ for $3 \mathrm{~h}$. Myo-inositol was used as an internal standard. The resulting monosaccharides were analyzed by high-performance anion-exchange chromatography on a CarboPac PA-10 anion exchange column $(4.6 \times$ $250 \mathrm{~mm}$; Dionex) using a pulsed amperometric detector (HPAEC-PAD; Dionex ICS 3000 system). Monosaccharides were eluted, at $1 \mathrm{ml} \mathrm{min} \mathrm{m}^{-1}$, using a linear saline gradient of $100 \mathrm{mM} \mathrm{NaOH}$ to $100 \mathrm{mM} \mathrm{NaOH}$ and $300 \mathrm{mM}$ sodium acetate over $20 \mathrm{~min}$.

Prior glycosidic linkage analysis uronic acid residues were converted to 6,6-dideuterio neutral sugar derivatives as previously described (Mélida et al. 2015b). Polysaccharide networks in the dry carboxyl reduced cell-wall samples $(0.1 \mathrm{mg})$ were methylated according to Mélida et al. (2013). Partially methylated polysaccharides were hydrolyzed in the presence of $2 \mathrm{M} \mathrm{TFA}$ at $121^{\circ} \mathrm{C}$ for $3 \mathrm{~h}$ and were converted to permethylated aldiol acetates (Albersheim et al. 1967). The latter were separated and were analyzed on a SP-2380 capillary column $(30 \mathrm{~m} \times$ $0.25 \mathrm{~mm}$ i.d.; Supelco) using a HP-6890 gas chromatography system and a HP-5973 electron-impact mass spectrometer (EI-MS) as a detector (Agilent Technologies). The temperature program increased from 180 to $230^{\circ} \mathrm{C}$ at a rate of $1.5^{\circ} \mathrm{C} \mathrm{min}{ }^{-1}$. The mass spectra of the fragments obtained from the permethylated alditol acetates (EI-MS) were compared with those of reference derivatives and by comparison with available data from the Complex Carbohydrate Research Center (CCRC) spectral database (University of Georgia, Athens, GA, U.S.A.).

\section{Aequorin luminescence measurements.}

Arabidopsis 8-day-old liquid-grown transgenic seedlings $(n>8)$ of ecotype Col-0 carrying the calcium reporter aequorin $\left(\mathrm{Col}-0^{\mathrm{AEQ}}\right.$ ) (Knight et al. 1991) were used for cytoplasmic calcium $\left(\mathrm{Ca}_{\text {cyt }}^{2+}\right)$ measurements as previously described (Bacete et al. 2017).

\section{Immunoblot analysis of MAPK activation.}

Twelve-day-old seedlings were treated with different cellwall fractions and MAMPs or DAMPs. The seedlings were then harvested at the indicated timepoints. Immunoblots were performed as previously described (Mélida et al. 2018).

\section{Gene expression analyses.}

qRT-PCR and detection were carried out in a 7300 real-time PCR system (Thermo Fisher). Reactions were conducted in a final volume of $20 \mu \mathrm{l}$ with $10 \mu \mathrm{l}$ of $2 \times \mathrm{SYBR}$ green master mix (Roche Applied Science), $1 \mu \mathrm{M}$ of the oligonucleotides, and $10 \mathrm{ng}$ of cDNA. PCR conditions were as follows: $95^{\circ} \mathrm{C}$ for $10 \mathrm{~min}$ and then 45 cycles of $95^{\circ} \mathrm{C}$ for $15 \mathrm{~s}$ and $60^{\circ} \mathrm{C}$ for $1 \mathrm{~min}$. At the end of each experiment, a dissociation stage $\left(95^{\circ} \mathrm{C}\right.$ for $15 \mathrm{~s}, 60^{\circ} \mathrm{C}$ for $30 \mathrm{~s}$, and $95^{\circ} \mathrm{C}$ for $15 \mathrm{~s}$ ) was carried out to ensure that only single products were formed. The expression levels of each gene, relative to $U B C 21$ (At5g25760) expression, were determined using the Pfaffl method (Pfaffl 2001). The oligonucleotides used for qRT-PCR are summarized in Supplementary Table S9.

\section{MAMPs and DAMPs.}

In $\mathrm{Ca}^{2+}$ input, MAPK phosphorylation, and gene expression experiments, 1,4- $\beta$-D-(GlcNAc) $)_{6}$, derived from fungal chitin, and flg22, derived from bacterial flagella, were included as MAMP controls. 1,4- $\beta$-D- $(\text { GlcNAc) })_{6}$, (O-CHI6), purchased from Megazyme, was prepared from chitin; and flg22 was a synthetic peptide obtained from EZBiolab. Likewise, $\mathrm{OG}_{10-15}$ (1,4- $\alpha$-D-(GalA $\left.)_{10-15}\right)$ derived from homogalacturonan were included as a DAMP control. $\mathrm{OG}_{10-15}$, obtained from Elicityl, was generated from galacturonate polysaccharide hydrolysis with a $>99 \%$ purity.

\section{Metabolic profiling.}

Col-0 (25-day-old) and arr6-3 plants were collected, were ground in liquid nitrogen, and were freeze dried for $24 \mathrm{~h}$ under vacuum. Four biological replicates for each of these genotypes were further processed and analyzed, by Metabolon Inc., for global unbiased metabolite profiling as described previously (Ren et al. 2012).

\section{ACKNOWLEDGMENTS}

We thank P. Ranocha and A. Freydier for the initial selection of arr6-3 mutant. We also thank Plant Response Biotech, Semillas Fitó, and the NOBACTOME project team (M. Borja and R. Pérez, and T. Jahrman) for providing support and valuable discussions about ARR6 function.

\section{AUTHOR-RECOMMENDED INTERNET RESOURCES}

Bio-Analytic Resource for Plant Biology BAR ePlant database: http://bar.utoronto.ca/eplant

BioinfoGP FIESTA Viewer:

http://bioinfogp.cnb.csic.es/tools/FIESTA

CCRC spectral database:

http://ccrc.uga.edu/specdb/ms/pmaa/pframe.html

\section{LITERATURE CITED}

Albersheim, P., Nevins, D. J., English, P. D., and Karr, A. 1967. A method for the analysis of sugars in plant cell-wall polysaccharides by gas-liquid chromatography. Carbohydr. Res. 5:340-345.

Alonso-Simón, A., García-Angulo, P., Mélida, H., Encina, A., Álvarez, J. M., and Acebes, J. L. 2011. The use of FTIR spectroscopy to monitor modifications in plant cell wall architecture caused by cellulose biosynthesis inhibitors. Plant Signal. Behav. 6:1104-1110.

Argueso, C. T., Ferreira, F. J., Epple, P., To, J. P. C., Hutchison, C. E., Schaller, G. E., Dangl, J. L., and Kieber, J. J. 2012. Two-component elements mediate interactions between cytokinin and salicylic acid in plant immunity. PLoS Genet. 8:e1002448. 
Atkinson, N. J., and Urwin, P. E. 2012. The interaction of plant biotic and abiotic stresses: From genes to the field. J. Exp. Bot. 63:3523-3543

Bacete, L., Mélida, H., Miedes, E., and Molina, A. 2018. Plant cell wall-mediated immunity: Cell wall changes trigger disease resistance responses. Plant J. 93:614-636.

Bacete, L., Mélida, H., Pattathil, S., Hahn, M. G., Molina, A., and Miedes, E. 2017. Characterization of plant cell wall damage-associated molecular patterns regulating immune responses. Pages 13-23 in: Methods in Molecular Biology. Springer, New York.

Bari, R., and Jones, J. D. G. 2009. Role of plant hormones in plant defence responses. Plant Mol. Biol. 69:473-488.

Bellés, J. M., Garro, R., Pallás, V., Fayos, J., Rodrigo, I., and Conejero, V. 2006. Accumulation of gentisic acid as associated with systemic infections but not with the hypersensitive response in plant-pathogen interactions. Planta 223:500-511.

Benedetti, M., Pontiggia, D., Raggi, S., Cheng, Z., Scaloni, F., Ferrari, S., Ausubel, F. M., Cervone, F., and De Lorenzo, G. 2015. Plant immunity triggered by engineered in vivo release of oligogalacturonides, damageassociated molecular patterns. Proc. Natl. Acad. Sci. U.S.A. 112: 5533-5538.

Berrocal-Lobo, M., Molina, A., and Solano, R. 2002. Constitutive expression of ETHYLENE-RESPONSE-FACTOR1 in Arabidopsis confers resistance to several necrotrophic fungi. Plant J. 29:23-32.

Bethke, G., Thao, A., Xiong, G., Li, B., Soltis, N. E., Hatsugai, N., Hillmer, R. A., Katagiri, F., Kliebenstein, D. J., Pauly, M., and Glazebrook, J. 2016. Pectin biosynthesis is critical for cell wall integrity and immunity in Arabidopsis thaliana. Plant Cell 28:537-556.

Bethke, G., Unthan, T., Uhrig, J. F., Pöschl, Y., Gust, A. A., Scheel, D., and Lee, J. 2009. Flg22 regulates the release of an ethylene response factor substrate from MAP kinase 6 in Arabidopsis thaliana via ethylene signaling. Proc. Natl. Acad. Sci. U.S.A. 106:8067-8072.

Bhargava, A., Clabaugh, I., To, J. P., Maxwell, B. B., Chiang, Y. H., Schaller, G. E., Loraine, A., and Kieber, J. J. 2013. Identification of cytokinin-responsive genes using microarray meta-analysis and RNASeq in Arabidopsis. Plant Physiol. 162:272-294.

Boller, T., and Felix, G. 2009. A renaissance of elicitors: Perception of microbe-associated molecular patterns and danger signals by patternrecognition receptors. Annu. Rev. Plant Biol. 60:379-406.

Boudsocq, M., and Sheen, J. 2013. CDPKs in immune and stress signaling Trends Plant Sci. 18:30-40.

Boudsocq, M., Willmann, M. R., McCormack, M., Lee, H., Shan, L., He, P. Bush, J., Cheng, S. H., and Sheen, J. 2010. Differential innate immune signalling via $\mathrm{Ca}^{2+}$ sensor protein kinases. Nature 464:418-422.

Boutrot, F., and Zipfel, C. 2017. Function, discovery, and exploitation of plant pattern recognition receptors for broad-spectrum disease resistance. Annu. Rev. Phytopathol. 55:257-286.

Brenner, W. G., Ramireddy, E., Heyl, A., and Schmülling, T. 2012. Gene regulation by cytokinin in Arabidopsis. Front. Plant Sci. 3:8.

Buxdorf, K., Yaffe, H., Barda, O., and Levy, M. 2013. The effects of glucosinolates and their breakdown products on necrotrophic fungi. PLoS One 8:e70771

Carpita, N. C., Defernez, M., Findlay, K., Wells, B., Shoue, D. A., Catchpole, G., Wilson, R. H., and McCann, M. C. 2001. Cell wall architecture of the elongating maize coleoptile. Plant Physiol. 127:551-565.

Choi, H. W., and Klessig, D. F. 2016. DAMPs, MAMPs, and NAMPs in plant innate immunity. BMC Plant Biol. 16:232.

Choi, J., Choi, D., Lee, S., Ryu, C. M., and Hwang, I. 2011. Cytokinins and plant immunity: Old foes or new friends? Trends Plant Sci. 16:388-394.

Choi, J., Huh, S. U., Kojima, M., Sakakibara, H., Paek, K. H., and Hwang, I. 2010. The cytokinin-activated transcription factor ARR2 promotes plant immunity via TGA3/NPR1-dependent salicylic acid signaling in Arabidopsis. Dev. Cell 19:284-295.

Claverie, J., Balacey, S., Lemaître-Guillier, C., Brulé, D., Chiltz, A., Granet, L., Noirot, E., Daire, X., Darblade, B., Héloir, M. C., and Poinssot, B. 2018. The cell wall-derived xyloglucan is a new DAMP triggering plant immunity in Vitis vinifera and Arabidopsis thaliana. Front. Plant Sci. 9: 1725 .

Clough, S. J., and Bent, A. F. 1998. Floral dip: A simplified method for Agrobacterium-mediated transformation of Arabidopsis thaliana. Plant J. 16:735-743.

Couto, D., and Zipfel, C. 2016. Regulation of pattern recognition receptor signalling in plants. Nat. Rev. Immunol. 16:537-552.

Davidsson, P., Broberg, M., Kariola, T., Sipari, N., Pirhonen, M., and Palva, E. T. 2017. Short oligogalacturonides induce pathogen resistance-associated gene expression in Arabidopsis thaliana. BMC Plant Biol. 17:19.

De Lorenzo, G., Ferrari, S., Cervone, F., and Okun, E. 2018. Extracellular DAMPs in plants and mammals: Immunity, tissue damage and repair Trends Immunol. 39:937-950.
Delgado-Cerezo, M., Sánchez-Rodríguez, C., Escudero, V., Miedes, E., Fernández, P. V., Jordá, L., Hernández-Blanco, C., Sánchez-Vallet, A. Bednarek, P., Schulze-Lefert, P., Somerville, S., Estevez, J. M., Persson, S., and Molina, A. 2012. Arabidopsis heterotrimeric G-protein regulates cell wall defense and resistance to necrotrophic fungi. Mol. Plant 5: 98-114

Denancé, N., Ranocha, P., Oria, N., Barlet, X., Rivière, M. P., Yadeta, K. A., Hoffmann, L., Perreau, F., Clément, G., Maia-Grondard, A., van den Berg, G. C. M., Savelli, B., Fournier, S., Aubert, Y., Pelletier, S., Thomma, B. P. H. J., Molina, A., Jouanin, L., Marco, Y., and Goffner, D. 2013b. Arabidopsis watl (walls are thin1)-mediated resistance to the bacterial vascular pathogen, Ralstonia solanacearum, is accompanied by cross-regulation of salicylic acid and tryptophan metabolism. Plant J. 73: 225-239.

Denancé, N., Sánchez-Vallet, A., Goffner, D., and Molina, A. 2013a. Disease resistance or growth: The role of plant hormones in balancing immune responses and fitness costs. Front. Plant Sci. 4:155.

Deslandes, L., Pileur, F., Liaubet, L., Camut, S., Can, C., Williams, K., Holub, E., Beynon, J., Arlat, M., and Marco, Y. 1998. Genetic characterization of RRS1, a recessive locus in Arabidopsis thaliana that confers resistance to the bacterial soilborne pathogen Ralstonia solanacearum. Mol. Plant-Microbe Interact. 11:659-667.

Digonnet, C., Martinez, Y., Denancé, N., Chasseray, M., Dabos, P., Ranocha, P., Marco, Y., Jauneau, A., and Goffner, D. 2012. Deciphering the route of Ralstonia solanacearum colonization in Arabidopsis thaliana roots during a compatible interaction: Focus at the plant cell wall. Planta 236:1419-1431.

Dodds, P. N., and Rathjen, J. P. 2010. Plant immunity: Towards an integrated view of plant-pathogen interactions. Nat. Rev. Genet. 11: 539-548.

Earley, K. W., Haag, J. R., Pontes, O., Opper, K., Juehne, T., Song, K., and Pikaard, C. S. 2006. Gateway-compatible vectors for plant functional genomics and proteomics. Plant J. 45:616-629.

Ellis, C., Karafyllidis, I., Wasternack, C., and Turner, J. G. 2002. The Arabidopsis mutant cevl links cell wall signaling to jasmonate and ethylene responses. Plant Cell 14:1557-1566.

Engelsdorf, T., Gigli-Bisceglia, N., Veerabagu, M., McKenna, J. F., Vaahtera, L., Augstein, F., Van der Does, D., Zipfel, C., and Hamann, T. 2018. The plant cell wall integrity maintenance and immune signaling systems cooperate to control stress responses in Arabidopsis thaliana. Sci. Signal. 11:eaao3070.

Engelsdorf, T., and Hamann, T. 2014. An update on receptor-like kinase involvement in the maintenance of plant cell wall integrity. Ann. Bot. 114:1339-1347

Escudero, V., Jordá, L., Sopeña-Torres, S., Mélida, H., Miedes, E., MuñozBarrios, A., Swami, S., Alexander, D., McKee, L. S., Sánchez-Vallet, A. Bulone, V., Jones, A. M., and Molina, A. 2017. Alteration of cell wall xylan acetylation triggers defense responses that counterbalance the immune deficiencies of plants impaired in the $\beta$-subunit of the heterotrimeric G-protein. Plant J. 92:386-399.

Ferrari, S., Galletti, R., Pontiggia, D., Manfredini, C., Lionetti, V., Bellincampi, D., Cervone, F., and De Lorenzo, G. 2008. Transgenic expression of a fungal endo-polygalacturonase increases plant resistance to pathogens and reduces auxin sensitivity. Plant Physiol. 146:669-681.

Ferrari, S., Savatin, D. V., Sicilia, F., Gramegna, G., Cervone, F., and Lorenzo, G. D. 2013. Oligogalacturonides: Plant damage-associated molecular patterns and regulators of growth and development. Front. Plant Sci. 4:49.

Galletti, R., Denoux, C., Gambetta, S., Dewdney, J., Ausubel, F. M., De Lorenzo, G., and Ferrari, S. 2008. The AtrbohD-mediated oxidative burs elicited by oligogalacturonides in Arabidopsis is dispensable for the activation of defense responses effective against Botrytis cinerea. Plant Physiol. 148:1695-1706.

Gigli-Bisceglia, N., Engelsdorf, T., Strnad, M., Vaahtera, L., Khan, G. A., Yamoune, A., Alipanah, L., Novák, O., Persson, S., Hejatko, J., and Hamann, T. 2018. Cell wall integrity modulates Arabidopsis thaliana cell cycle gene expression in a cytokinin- and nitrate reductasedependent manner. Development 145:dev166678.

Glazebrook, J. 2005. Contrasting mechanisms of defense against biotrophic and necrotrophic pathogens. Annu. Rev. Phytopathol. 43:205-227.

Hamann, T., Bennett, M., Mansfield, J., and Somerville, C. 2009. Identification of cell-wall stress as a hexose-dependent and osmosensitive regulator of plant responses. Plant J. 57:1015-1026.

Hanemian, M., Barlet, X., Sorin, C., Yadeta, K. A., Keller, H., Favery, B., Simon, R., Thomma, B. P., Hartmann, C., Crespi, M., Marco, Y., Tremousaygue, D., and Deslandes, L. 2016. Arabidopsis CLAVATA1 and CLAVATA2 receptors contribute to Ralstonia solanacearum pathogenicity through a miR169-dependent pathway. New Phytol. 211:502-515. 
Hass, C., Lohrmann, J., Albrecht, V., Sweere, U., Hummel, F., Yoo, S. D., Hwang, I., Zhu, T., Schäfer, E., Kudla, J., and Harter, K. 2004. The response regulator 2 mediates ethylene signalling and hormone signal integration in Arabidopsis. EMBO J. 23:3290-3302.

Hernández-Blanco, C., Feng, D. X., Hu, J., Sánchez-Vallet, A., Deslandes, L., Llorente, F., Berrocal-Lobo, M., Keller, H., Barlet, X., SánchezRodríguez, C., Anderson, L. K., Somerville, S., Marco, Y., and Molina, A. 2007. Impairment of cellulose synthases required for Arabidopsis secondary cell wall formation enhances disease resistance. Plant Cell 19: 890-903.

Hirsch, J., Deslandes, L., Feng, D. X., Balagué, C., and Marco, Y. 2002. Delayed symptom development in ein2-1, an Arabidopsis ethyleneinsensitive mutant, in response to bacterial wilt caused by Ralstonia solanacearum. Phytopathology 92:1142-1148.

Horák, J., Grefen, C., Berendzen, K. W., Hahn, A., Stierhof, Y. D., Stadelhofer, B., Stahl, M., Koncz, C., and Harter, K. 2008. The Arabidopsis thaliana response regulator ARR22 is a putative AHP phospho-histidine phosphatase expressed in the chalaza of developing seeds. BMC Plant Biol. 8:77.

Houston, K., Tucker, M. R., Chowdhury, J., Shirley, N., and Little, A. 2016. The plant cell wall: A complex and dynamic structure as revealed by the responses of genes under stress conditions. Front. Plant Sci. 7:984.

Hu, J., Barlet, X., Deslandes, L., Hirsch, J., Feng, D. X., Somssich, I., and Marco, Y. 2008. Transcriptional responses of Arabidopsis thaliana during wilt disease caused by the soil-borne phytopathogenic bacterium, Ralstonia solanacearum. PLoS One 3:e2589.

Huang, P.-Y., Catinot, J., and Zimmerli, L. 2016. Ethylene response factors in Arabidopsis immunity. J. Exp. Bot. 67:1231-1241.

Hwang, I., and Sheen, J. 2001. Two-component circuitry in Arabidopsis cytokinin signal transduction. Nature 413:383-389.

Hwang, I., Sheen, J., and Müller, B. 2012. Cytokinin signaling networks. Annu. Rev. Plant Biol. 63:353-380.

Kiba, T., Aoki, K., Sakakibara, H., and Mizuno, T. 2004. Arabidopsis response regulator, ARR22, ectopic expression of which results in phenotypes similar to the wol cytokinin-receptor mutant. Plant Cell Physiol. 45:1063-1077.

Klopffleisch, K., Phan, N., Augustin, K., Bayne, R. S., Booker, K. S., Botella, J. R., Carpita, N. C., Carr, T., Chen, J. G., Cooke, T. R., FrickCheng, A., Friedman, E. J., Fulk, B., Hahn, M. G., Jiang, K., Jorda, L., Kruppe, L., Liu, C., Lorek, J., McCann, M. C., Molina, A., Moriyama, E. N., Mukhtar, M. S., Mudgil, Y., Pattathil, S., Schwarz, J., Seta, S., Tan, M., Temp, U., Trusov, Y., Urano, D., Welter, B., Yang, J., Panstruga, R., Uhrig, J. F., and Jones, A. M. 2011. Arabidopsis G-protein interactome reveals connections to cell wall carbohydrates and morphogenesis. Mol. Syst. Biol. 7:532.

Knight, M. R., Campbell, A. K., Smith, S. M., and Trewavas, A. J. 1991. Transgenic plant aequorin reports the effects of touch and cold-shock and elicitors on cytoplasmic calcium. Nature 352:524-526.

Kondo, Y., Hirakawa, Y., Kieber, J. J., and Fukuda, H. 2011. CLE peptides can negatively regulate protoxylem vessel formation via cytokinin signaling. Plant Cell Physiol. 52:37-48.

Krishnakumar, V., Contrino, S., Cheng, C. Y., Belyaeva, I., Ferlanti, E. S., Miller, J. R., Vaughn, M. W., Micklem, G., Town, C. D., and Chan, A. P. 2017. ThaleMine: A warehouse for Arabidopsis data integration and discovery. Plant Cell Physiol. 58:e4.

Licausi, F., Ohme-Takagi, M., and Perata, P. 2013. APETALA2/ethylene responsive factor (AP2/ERF) transcription factors: Mediators of stress responses and developmental programs. New Phytol. 199:639-649.

Lionetti, V., Fabri, E., De Caroli, M., Hansen, A. R., Willats, W. G. T., Piro, G., and Bellincampi, D. 2017. Three pectin methylesterase inhibitors protect cell wall integrity for Arabidopsis immunity to Botrytis. Plant Physiol. 173:1844-1863.

Llorente, F., Alonso-Blanco, C., Sánchez-Rodriguez, C., Jorda, L., and Molina, A. 2005. ERECTA receptor-like kinase and heterotrimeric G protein from Arabidopsis are required for resistance to the necrotrophic fungus Plectosphaerella cucumerina. Plant J. 43:165-180.

Lugan, R., Niogret, M. F., Kervazo, L., Larher, F. R., Kopka, J., and Bouchereau, A. 2009. Metabolome and water status phenotyping of Arabidopsis under abiotic stress cues reveals new insight into ESK1 function. Plant Cell Environ. 32:95-108.

McCann, M. C., Hammouri, M., Wilson, R., Belton, P., and Roberts, K. 1992. Fourier transform infrared microspectroscopy is a new way to look at plant cell walls. Plant Physiol. 100:1940-1947.

Mélida, H., García-Angulo, P., Alonso-Simón, A., Encina, A., Alvarez, J., and Acebes, J. L. 2009. Novel type II cell wall architecture in dichlobenil-habituated maize calluses. Planta 229:617-631.

Mélida, H., Largo-Gosens, A., Novo-Uzal, E., Santiago, R., Pomar, F., García, P., García-Angulo, P., Acebes, J. L., Álvarez, J., and Encina, A. 2015a. Ectopic lignification in primary cellulose-deficient cell walls of maize cell suspension cultures. J. Integr. Plant Biol. 57:357-372.

Mélida, H., Sain, D., Stajich, J. E., and Bulone, V. 2015b. Deciphering the uniqueness of Mucoromycotina cell walls by combining biochemical and phylogenomic approaches. Environ. Microbiol. 17:1649-1662.

Mélida, H., Sandoval-Sierra, J. V., Diéguez-Uribeondo, J., and Bulone, V. 2013. Analyses of extracellular carbohydrates in oomycetes unveil the existence of three different cell wall types. Eukaryot. Cell 12:194-203.

Mélida, H., Sopeña-Torres, S., Bacete, L., Garrido-Arandia, M., Jordá, L., López, G., Muñoz-Barrios, A., Pacios, L. F., and Molina, A. 2018. Nonbranched $\beta$-1,3-glucan oligosaccharides trigger immune responses in Arabidopsis. Plant J. 93:34-49.

Meng, X., and Zhang, S. 2013. MAPK cascades in plant disease resistance signaling. Annu. Rev. Phytopathol. 51:245-266.

Miedes, E., Vanholme, R., Boerjan, W., and Molina, A. 2014. The role of the secondary cell wall in plant resistance to pathogens. Front. Plant Sci. $5: 358$.

Moffat, C. S., Ingle, R. A., Wathugala, D. L., Saunders, N. J., Knight, H., and Knight, M. R. 2012. ERF5 and ERF6 play redundant roles as positive regulators of JA/Et-mediated defense against Botrytis cinerea in Arabidopsis. PLoS One 7:e35995.

Mouille, G., Robin, S., Lecomte, M., Pagant, S., and Höfte, H. 2003. Classification and identification of Arabidopsis cell wall mutants using Fourier-transform infrared (FT-IR) microspectroscopy. Plant J. 35: 393-404.

Nafisi, M., Fimognari, L., and Sakuragi, Y. 2015. Interplays between the cell wall and phytohormones in interaction between plants and necrotrophic pathogens. Phytochemistry 112:63-71.

Nakano, T., Suzuki, K., Fujimura, T., and Shinshi, H. 2006. Genome-wide analysis of the ERF gene family in Arabidopsis and rice. Plant Physiol. 140:411-432.

Naseem, M., Kaltdorf, M., and Dandekar, T. 2015. The nexus between growth and defence signalling: Auxin and cytokinin modulate plant immune response pathways. J. Exp. Bot. 66:4885-4896.

Naseem, M., Wölfling, M., and Dandekar, T. 2014. Cytokinins for immunity beyond growth, galls and green islands. Trends Plant Sci. 19:481-484.

Návarová, H., Bernsdorff, F., Döring, A. C., and Zeier, J. 2012. Pipecolic acid, an endogenous mediator of defense amplification and priming, is a critical regulator of inducible plant immunity. Plant Cell 24:5123-5141.

O’Brien, J. A., and Benková, E. 2013. Cytokinin cross-talking during biotic and abiotic stress responses. Front. Plant Sci. 4:451.

Pesquet, E., Ranocha, P., Legay, S., Digonnet, C., Barbier, O., Pichon, M., and Goffner, D. 2005. Novel markers of xylogenesis in zinnia are differentially regulated by auxin and cytokinin. Plant Physiol. 139: 1821-1839

Pfaffl, M. W. 2001. A new mathematical model for relative quantification in real-time RT-PCR. Nucleic Acids Res. 29:e45.

Pieterse, C. M. J., Van der Does, D., Zamioudis, C., Leon-Reyes, A., and Van Wees, S. C. M. 2012. Hormonal modulation of plant immunity. Annu. Rev. Cell Dev. Biol. 28:489-521.

Pils, B., and Heyl, A. 2009. Unraveling the evolution of cytokinin signaling. Plant Physiol. 151:782-791.

Raiola, A., Lionetti, V., Elmaghraby, I., Immerzeel, P., Mellerowicz, E. J., Salvi, G., Cervone, F., and Bellincampi, D. 2011. Pectin methylesterase is induced in Arabidopsis upon infection and is necessary for a successful colonization by necrotrophic pathogens. Mol. Plant-Microbe Interact. 24:432-440.

Ramírez, V., Xiong, G., Mashiguchi, K., Yamaguchi, S., and Pauly, M. 2018. Growth- and stress-related defects associated with wall hypoacetylation are strigolactone-dependent. Plant Dir. 2:e00062.

Ren, M., Venglat, P., Qiu, S., Feng, L., Cao, Y., Wang, E., Xiang, D., Wang, J., Alexander, D., Chalivendra, S., Logan, D., Mattoo, A., Selvaraj, G., and Datla, R. 2012. Target of rapamycin signaling regulates metabolism, growth, and life span in Arabidopsis. Plant Cell 24:4850-4874.

Ridley, B. L., O’Neill, M. A., and Mohnen, D. 2001. Pectins: Structure, biosynthesis, and oligogalacturonide-related signaling. Phytochemistry 57:929-967.

Robert-Seilaniantz, A., Grant, M., and Jones, J. D. G. 2011. Hormone crosstalk in plant disease and defense: More than just jasmonatesalicylate antagonism. Annu. Rev. Phytopathol. 49:317-343.

Sakuma, Y., Liu, Q., Dubouzet, J. G., Abe, H., Shinozaki, K., and Yamaguchi-Shinozaki, K. 2002. DNA-binding specificity of the ERF/AP2 domain of Arabidopsis DREBs, transcription factors involved in dehydration- and cold-inducible gene expression. Biochem. Biophys. Res. Commun. 290:998-1009.

Sánchez-Rodríguez, C., Estévez, J. M., Llorente, F., Hernández-Blanco, C., Jordá, L., Pagán, I., Berrocal, M., Marco, Y., Somerville, S., and Molina, 
A. 2009. The ERECTA receptor-like kinase regulates cell wall-mediated resistance to pathogens in Arabidopsis thaliana. Mol. Plant-Microbe Interact. 22:953-963.

Sánchez-Vallet, A., Ramos, B., Bednarek, P., López, G., Piślewska-Bednarek, M., Schulze-Lefert, P., and Molina, A. 2010. Tryptophan-derived secondary metabolites in Arabidopsis thaliana confer non-host resistance to necrotrophic Plectosphaerella cucumerina fungi. Plant J. 63:115-127.

Séné, C., McCann, M. C., Wilson, R. H., and Grinter, R. 1994. Fouriertransform Raman and Fourier-transform infrared spectroscopy (an investigation of five higher plant cell walls and their components). Plant Physiol. 106:1623-1631.

Shi, Y., Tian, S., Hou, L., Huang, X., Zhang, X., Guo, H., and Yang, S. 2012. Ethylene signaling negatively regulates freezing tolerance by repressing expression of $C B F$ and type-A ARR genes in Arabidopsis. Plant Cell 24: 2578-2595.

Shigenaga, A. M., Berens, M. L., Tsuda, K., and Argueso, C. T. 2017. Towards engineering of hormonal crosstalk in plant immunity. Curr. Opin. Plant Biol. 38:164-172.

Sopeña-Torres, S., Jordá, L., Sánchez-Rodríguez, C., Miedes, E., Escudero, V., Swami, S., López, G., Piślewska-Bednarek, M., Lassowskat, I., Lee, J., Gu, Y., Haigis, S., Alexander, D., Pattathil, S., Muñoz-Barrios, A., Bednarek, P., Somerville, S., Schulze-Lefert, P., Hahn, M. G., Scheel, D., and Molina, A. 2018. YODA MAP3K kinase regulates plant immune responses conferring broad-spectrum disease resistance. New Phytol. 218:661-680.

To, J. P., Deruère, J., Maxwell, B. B., Morris, V. F., Hutchison, C. E., Ferreira, F. J., Schaller, G. E., and Kieber, J. J. 2007. Cytokinin regulates type-A Arabidopsis response regulator activity and protein stability via two-component phosphorelay. Plant Cell 19:3901-3914.

To, J. P., Haberer, G., Ferreira, F. J., Deruère, J., Mason, M. G., Schaller, G. E., Alonso, J. M., Ecker, J. R., and Kieber, J. J. 2004. Type-A Arabidopsis response regulators are partially redundant negative regulators of cytokinin signaling. Plant Cell 16:658-671.

Tran, L. S. P., Urao, T., Qin, F., Maruyama, K., Kakimoto, T., Shinozaki, K., and Yamaguchi-Shinozaki, K. 2007. Functional analysis of AHK1/ATHK1 and cytokinin receptor histidine kinases in response to abscisic acid, drought, and salt stress in Arabidopsis. Proc. Natl. Acad. Sci. U.S.A. 104: 20623-20628.

Trouvelot, S., Héloir, M. C., Poinssot, B., Gauthier, A., Paris, F., Guillier, C., Combier, M., Trdá, L., Daire, X., and Adrian, M. 2014. Carbohydrates in plant immunity and plant protection: Roles and potential application as foliar sprays. Front. Plant Sci. 5:592.

Vaahtera, L., Schulz, J., and Hamann, T. 2019. Cell wall integrity maintenance during plant development and interaction with the environment. Nat. Plants 5:924-932.

Vogel, J. P., Raab, T. K., Schiff, C., and Somerville, S. C. 2002. PMR6, a pectate lyase-like gene required for powdery mildew susceptibility in Arabidopsis. Plant Cell 14:2095-2106.

Voxeur, A., Habrylo, O., Guénin, S., Miart, F., Soulié, M. C., Rihouey, C., Pau-Roblot, C., Domon, J. M., Gutierrez, L., Pelloux, J., Mouille, G., Fagard, M., Höfte, H., and Vernhettes, S. 2019. Oligogalacturonide production upon Arabidopsis thaliana-Botrytis cinerea interaction. Proc. Natl. Acad. Sci. U.S.A. 116:19743-19752.

Voxeur, A., and Höfte, H. 2016. Cell wall integrity signaling in plants: "To grow or not to grow that's the question". Glycobiology 26:950-960.

Wang, P., Du, Y., Zhao, X., Miao, Y., and Song, C. P. 2013. The MPK6ERF6-ROS-responsive cis-acting Element7/GCC box complex modulates oxidative gene transcription and the oxidative response in Arabidopsis. Plant Physiol. 161:1392-1408.

Weingart, H., Völksch, B., and Ullrich, M. S. 1999. Comparison of ethylene production by Pseudomonas syringae and Ralstonia solanacearum Phytopathology 89:360-365.

Wolf, S., Hématy, K., and Höfte, H. 2012. Growth control and cell wall signaling in plants. Annu. Rev. Plant Biol. 63:381-407.

Wormit, A., Butt, S. M., Chairam, I., McKenna, J. F., Nunes-Nesi, A., Kjaer, L., O’Donnelly, K., Fernie, A. R., Woscholski, R., Barter, M. C. L., and Hamann, T. 2012. Osmosensitive changes of carbohydrate metabolism in response to cellulose biosynthesis inhibition. Plant Physiol. 159: $105-117$.

Xin, Z., Mandaokar, A., Chen, J., Last, R. L., and Browse, J. 2007. Arabidopsis ESK1 encodes a novel regulator of freezing tolerance. Plant J. 49:786-799.

Xu, F., Liu, Z., Xie, H., Zhu, J., Zhang, J., Kraus, J., Blaschnig, T., Nehls, R., and Wang, H. 2014. Increased drought tolerance through the suppression of ESKMO1 gene and overexpression of $C B F$-related genes in Arabidopsis. PLoS One 9:e106509.

Zhou, N., Tootle, T. L., Tsui, F., Klessig, D. F., and Glazebrook, J. 1998. PAD4 functions upstream from salicylic acid to control defense responses in Arabidopsis. Plant Cell 10:1021-1030. 